University of Zurich

Department of Economics

Working Paper Series

ISSN 1664-7041 (print)

ISSN 1664-705X (online)

Working Paper No. 274

\title{
Intergenerational Mobility in the 19th Century: Micro-Level Evidence from the City of Zurich
}

Giacomin Favre, Joël Floris and Ulrich Woitek

January 2018 


\title{
Intergenerational Mobility in the $19^{\text {th }}$ Century
}

\author{
Micro-Level Evidence from the City of Zurich
}

\author{
Giacomin Favre*, Joël Floris`, and Ulrich Woitek ${ }^{\ddagger}$
}

\begin{abstract}
SUMMARY
We analyze social mobility of decennial citizenry cohorts of Zurich born between 1780 and 1870 . We categorize individuals according to their occupations and use different measures to show the level, change, and components of intergenerational mobility. Mobility was imperfect and weakly decreasing over time. Both level and change are driven by intergenerational persistence of occupations with a low socioeconomic position and low transition between low and high socioeconomic position.
\end{abstract}

JEL-Classification: J62, N33, N34

Keywords: Social Mobility, Occupational Mobility, 19th Century, Switzerland

\footnotetext{
*Corresponding author: University of Zurich, Department of Economics, Zürichbergstr. 14, 8032 Zurich; email: giacomin.favre@econ.uzh.ch.

${ }^{\dagger}$ University of Zurich, Institute for Evolutionary Medicine, Winterthurerstr. 190, 8057 Zurich; email: joel.floris@iem.uzh.ch.

$\ddagger$ University of Zurich, Department of Economics, Zürichbergstr. 14, 8032 Zurich; email: ulrich.woitek@econ.uzh.ch.
} 


\section{Introduction}

Economic inequality is on the rise again, reaching levels similar to the end of the $19^{\text {th }}$ century. Piketty $(2014$, p. 65) points out that lack of intergenerational mobility is a very important aspect of inequality. Hence, decomposing mobility into its components is central to understanding inequality. We describe changes in the level of occupational mobility in the city of Zurich from the late $18^{\text {th }}$ to the end of the $19^{\text {th }}$ century, and identify the crucial parts of the mobility table. Our data set contains rich information on the universe of Zurich's adult male citizens at several points in time over an entire century. This information allows us to categorize individuals with respect to occupation and to construct decennial measures of mobility. The measures provide a more continuous picture of changes in mobility than usually analyzed in the literature. Moreover, we do not have to rely on a linking mechanism between generations, because we directly observe family relationship. Our main finding is a slight decrease in mobility, mainly driven by the intergenerational persistence of occupations with low socioeconomic position.

As the rest of Switzerland (e.g. Veyrassat, 2012), the city of Zurich experienced rapid economic development during the $19^{\text {th }}$ century, accompanied by structural change. In the period from 1812 to 1888, the population of the city and its surrounding municipalities increased more than tenfold. After the incorporation of the surrounding municipalities into the city area in 1893, Zurich became the most populous city of Switzerland (Behrens, 2015). Zurich turned not only into an economic metropolis but also a financial center, traffic hub, and a major center of education and research (Behrens, 2015; Illi and König, 2017). Phenomena such as the growth of the textile industry, the construction and expansion of the railway, the formation of the Credit Suisse and similar institutions, and the foundation of the two universities (University of Zurich and ETH) were both causes and consequences of immense economic growth. On the federal level, the constitution of 1848 and its revision in 1874 set the institutional framework for this development, with reforms such as the introduction of the freedom of movement and the freedom of trade (Kley, 2011; Kury, 2012). 
Figure 1 illustrates the changes in the structure of the labor market for Zurich citizens as an important aspect of this development, with some occupations gaining and others losing importance with respect to their relative share in the labor force.

Figure 1: Occupations with largest changes in labor force share.

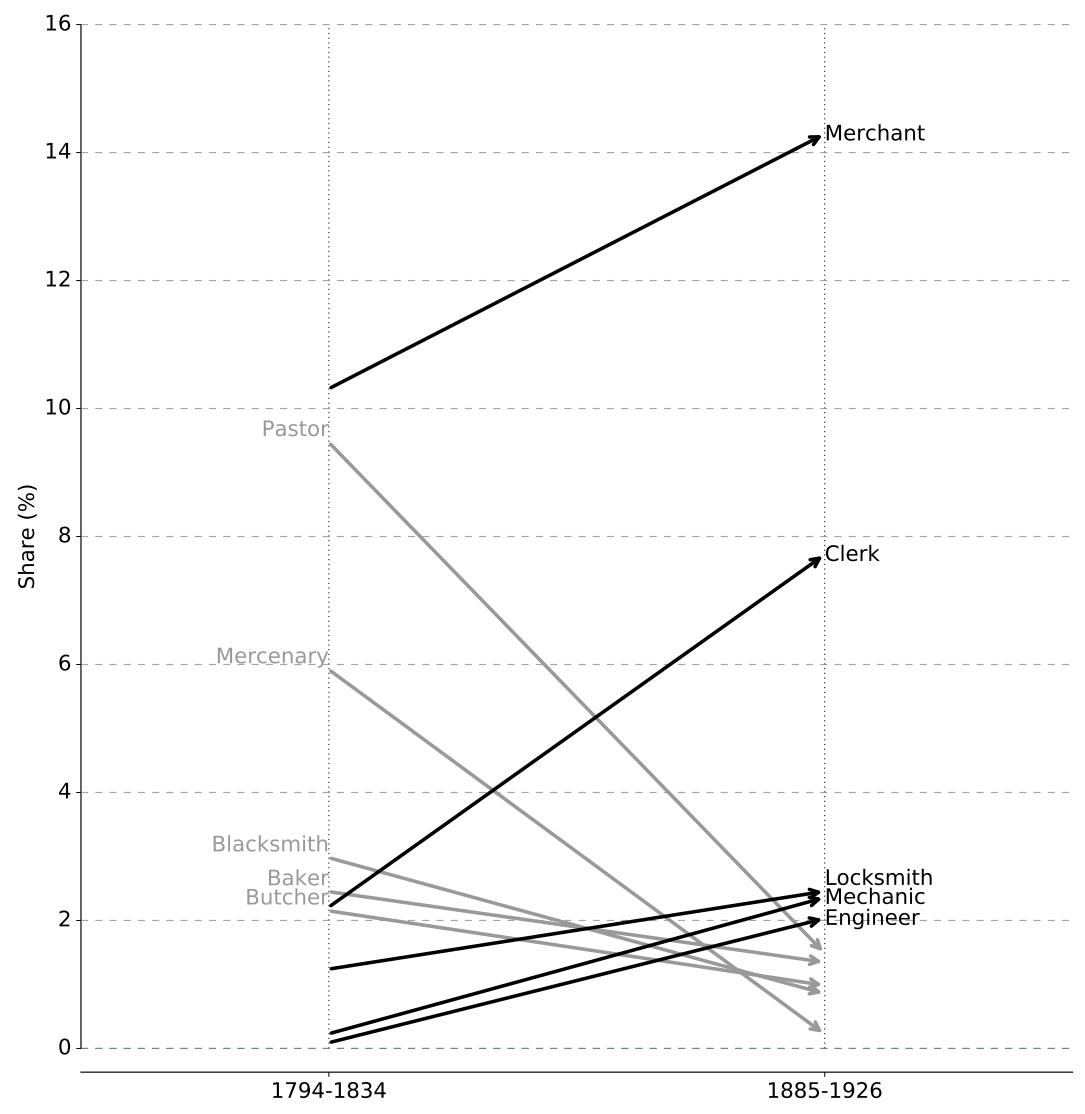

Note: The shares are based on the occupations of Zurich citizens. The relatively high share of protestant priests in 1794-1834 points toward the importance of Zurich as a religious center. Although the Zurich based reformator Huldrych Zwingli (1484-1531) started to preach against the mercenary service already in 1515 (Gordon, 2002, p. 51-53), it stayed an accepted occupation until the foundation of the federal state in 1848 .

Zurich's political history in the $19^{\text {th }}$ century was marked by a progressive democratization. Liberal forces were able to break the political power of the 
conservative forces in the 1830s. After the liberal founding of the federal state in 1848, the political dominance of the liberals and the representative system that they shaped were reversed in Zurich in the 1860s by the introduction of direct-democratic instruments (Behrens, 2015).

What are the consequences of these economic and institutional changes for social mobility? Going as far back as to de Tocqueville's work on the democracy in America from 1835, there is the expectation of a positive relationship between democracy and mobility. Similarly, one would expect industrialization to increase both upward and downward mobility. As Landes (2003, p. 546) puts it, "A competitive industrial system [...] will increase social mobility, raising the gifted, ambitious and lucky, and lowering the inept, lazy, ill-fortuned".

However, the recent literature shows that these expectations might be misleading, and our result provides further evidence for this finding. Acemoglu et al. (2016) demonstrate that democratic processes can actually reduce social mobility. With respect to industrialization in the United States, Blau and Duncan (1967) suggest increasing levels of mobility. The British example provides mixed evidence. While Long (2013) finds very high mobility rates during the Industrial Revolution, the results of Humphries (2010, p. 222-229), Clark (2014), Clark and Cummins (2014, 2015), and Clark et al. (2015) point in the opposite direction. On the other hand, Dribe et al. (2015) finds that absolute and relative mobility in rural Sweden increased with industrialization. According to Schüren (1989), larger German cities exhibited reduced chances of mobility after 1870, while horizontal mobility increased.

There is a large body of research on social mobility in the fields of economics, history, and sociology. ${ }^{1}$ For the main part of our analysis, we follow the approach of Long and Ferrie (2013) and analyze mobility tables. Instead, Clark (2014) and Clark et al. (2015) propose to use the persistence of surname shares in elite groups as a measure for mobility, which, to some extent, over-

1 Black and Devereux (2011) provide a review of recent literature on intergenerational mobility in general. 
comes the problem of attenuation bias (e.g. Clark, 2014, 108-113). Barone and Mocetti (2016) apply this method to look at long-run intergenerational mobility in the city of Florence. These studies show a very high persistence in social status over time. Olivetti and Paserman (2015) analyze fatherdaughter mobility in the 19th century US employing a novel strategy related to first names. Dribe and Svensson (2008), Dribe et al. (2015), Dribe and Helgertz (2016), and Lindahl et al. (2015) describe mobilty in 19th century Sweden. Among these, Dribe and Helgertz (2016) and Lindahl et al. (2015) belong to the fast growing branch of research on multi-generational mobility looking at a potential influence of grandfathers and distant relatives. ${ }^{2}$

For Switzerland, the studies of Falcon (2012, 2013, 2016), Jann and Combet (2012), and Jann and Seiler (2014) analyze intergenerational mobility in the 20th century. While Falcon $(2012,2013,2016)$ finds a relatively constant level of mobility, Jann and Combet (2012) and Jann and Seiler (2014) show either slightly decreasing or u-shaped levels of mobility, depending on the specific categorization. Compared to the other studies on Switzerland, we analyze individuals born between 1780 and 1870, and narrow the focus down geographically, since we restrict the analysis to the city of Zurich. An advantage of this approach is that it provides a more homogeneous sample, which helps reducing the random influences problem pointed out by Clark (2014).

\section{Data and Methods}

\subsection{Data}

Our data set is based on 24 editions of the directory of citizens of the city of Zurich (original title: Verzeichniß der Bürger der Stadt Zürich) in the period 1794-1926. The directories contain information on all adult male citizens of Zurich, such as a list of all male relatives, the year of birth, occupations, and

2 See Solon (2015) for an overview over the mixed evidence on the causal influence of distant relatives. In this paper, we follow the standard one-generational approach. 
the exact address within Zurich or place of residence outside the city. This information enables us to follow individuals over time and to reconstruct the male lineage for almost all citizens. Especially the direct reference of all male relatives is a major advantage when analyzing social mobility, as we do not need any linking mechanism between generations.

With respect to the institutional framework, the citizens of Zurich were a relatively homogeneous group. They shared the same rights and had to fulfill the same obligations. The rights of a citizen included voting rights (for males), access to pauper relief, and the right to use community resources. ${ }^{3}$ Citizenship in the city of Zurich could be obtained in three ways (Wirth, 1875, Vol. 2, p. 29-33): by birth, by marriage with a citizen (for females), or by paying a fee. Female citizens lost the citizenship in their home municipality when marrying a citizen from another municipality. Besides having to pay the fee, individuals wishing to join a municipality had to proof good reputation and pass a property threshold. They had to prove their membership in the Christian church as well, but this rule was abolished after 1866 . The fee was high and could vary within certain limits. The level depended on regional origin: it was highest for foreigners, followed by the fee for citizens from other Swiss cantons, and it was lowest for citizens from other municipalities within the canton of Zurich. Thus, it provided a barrier to geographical mobility. ${ }^{4}$ In total, our data set contains over 18,000 individuals born between 1708 and 1926, constituting more than 10,000 father-son pairs and 6,000 different families with up to seven generations. To analyze social mobility, we categorize

3 Besides citizens, the population of a municipality also consisted of registered inhabitants (Niedergelassene) and foreign temporary residents (Aufenthalter). One key difference to citizens was that registered inhabitants and temporary residents were not allowed to vote on the municipality level.

4 In 1813, the fee of purchasing the citizenship was 1500 Gulden for former citizens of other municipalities within the canton of Zurich, 2000 Gulden for citizens from another Swiss canton, and 2500 Gulden for foreigners (Citizens' Directory, Hofmeister 1813). Using the official exchange rate of Gulden to the Swiss Franc of 2.29 (Bundesblatt 1851, $1(18) 335 f f$, we can compare the fees with data from the tax register. We find that only very few top earners within the city had an annual income comparable to these levels. 
citizens according to their occupation at the approximate age of 40, using the three-dimensional classification described in Schüren (1989). The dimensions are socioeconomic position (SEP), employment relationship (position), and employment sector (Appendix, Table 5). The distribution across positions and sectors differs strongly across SEPs suggesting intersections between the three dimensions (Appendix, Table 6). For the main part of our analysis, we use the first dimension, SEP. ${ }^{5}$ We exclude farmers, since their share is negligible. The distributions of taxable wealth and income conditional on SEP validates the classification with respect to economic status (Figures 2a and $2 \mathrm{~b})$.

Figure 2: Income and wealth distributions by SEP.

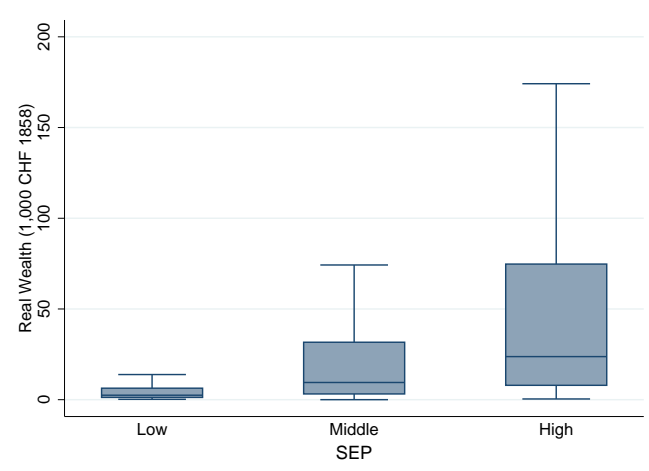

(a) Wealth distribution in each SEP.

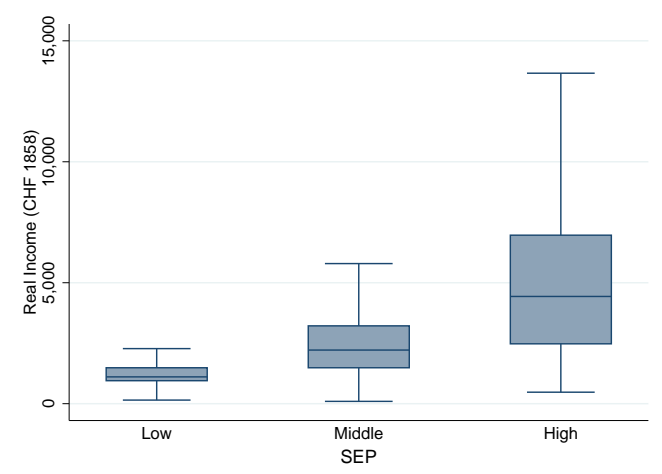

(b) Income distribution in each SEP.

Note: The boxplots exclude outliers. We exclude individuals without taxable income and wealth. The tax data are from the municipality and state tax registers (Gemeindesteuerregister and Staatssteuerregister) of the city of Zurich in the years 1832, 1851, 1858, 1893, 1904, 1912, and 1929.

Since it was possible to acquire a citizenship not only by birth, the set of families increases over time. This implies that the inclusion of all families would lead to a decreasing comparability over time because of selection. There-

5 There are two additional reasons for why we mainly employ the SEP categorization. First, the SEP categories are ordinal, while a ranking is difficult to achieve with the other two classifications. Second, the higher number of categories in the other classifications leads to problems with obtaining a sufficient number of observations per category. 
fore, we analyze two (overlapping) sub-samples. Our main sample (C1820) consists of father-son pairs from families that held citizenship already before 1820. An advantage of this choice is that it increases homogeneity of the data and helps to smooth out random influences on social status (Clark, 2014, p. 108-113). However, some individuals from these families left the city to live abroad, which did not lead to an automatic loss of citizenship, and hence, they are still in our data set. This feature avoids selection bias due to geographic (im)mobility, but it shifts the focus of the analyses away from the city towards its citizenry. Therefore, we construct a second sample (ZH) which includes all citizens spending most of their lifetime within the city. ${ }^{6}$ Table 1 shows that there are differences between the sons and the fathers within each sample, especially with respect to the age at which we classify SEP. Some fathers are older than 40 when they are on record for the first time. At the same time, some sons are younger than 40 in the last citizens directory they are mentioned in. ${ }^{7}$ High SEP fathers had more sons than middle or low SEP fathers, and were older at the birth of their first son. Fathers with more than one son were on average younger at the birth of their first son. C1820 fathers had on average more sons than ZH fathers, but the average age at birth of the first son is similar (Appendix, Table 8). These differences persisted roughly over time. Moreover, there is no clear trend in number of sons or age at birth of the first son in either of the samples (Appendix, Table 9).

6 To be included, citizens had to be recorded to having lived in the city of Zurich in at least one third of the directories in which they appear. In addition, their fathers had to fulfill the same condition or to be living in the city at the birth of the son.

7 The age at which we classify SEP ranges from 20 to 80 . However, the registries include information for the former occupations of retired individuals justifying their inclusion. A robustness check excluding all individuals younger than 30 or older than 50 shows results qualitatively similar to the evidence presented here. 
Table 1: Descriptive statistics.

\begin{tabular}{llrr}
\hline Sample & Characteristic & Sons & Fathers \\
\hline \hline \multirow{2}{*}{ C1820 } & Low SEP & $33.92 \%$ & $34.7 \%$ \\
& Middle SEP & $44.67 \%$ & $42.79 \%$ \\
& High SEP & $21.41 \%$ & $22.51 \%$ \\
& Age at observed SEP & 36.83 & 43.76 \\
& Number of Observations & 5091 & 2683 \\
\hline \multirow{2}{*}{ ZH } & Low SEP & $35.94 \%$ & $41.72 \%$ \\
& Middle SEP & $49.69 \%$ & $46.5 \%$ \\
& High SEP & $14.36 \%$ & $11.78 \%$ \\
& Age at observed SEP & 34.06 & 46.86 \\
& Number of Observations & 5409 & 3490 \\
\hline
\end{tabular}

Note: see Table 7 in the appendix for the descriptive statistics of the entire data set.

Figure 3 offers a less static descriptive statistic of the two samples, in line with the structural change related to the industrialization in Zurich (Section 1). It shows the relative frequency of the occupational categories in the three dimensions of Schüren (1989) over time. Due to the incorporation of surrounding municipalities, the area and population of the city increased in 1893. Overall, there is a concentration towards middle SEP. The differences between the two samples suggest that the more established C1820 families had, on average, a higher SEP than the ZH citizens. Regarding the employment status (Position), there is a shift away from civil servants and journeymen/masters towards employees and self-employed. C1820 individuals tended to work as civil servants more often at the beginning of the period. There is an increase in the share working in the trade, banking, insurance, and transport sector. The share of the industry sector decreases slightly, while there is a more pronounced decrease in the share of the combined professionals, public, clergy, and agriculture sector. 
Figure 3: Occupational structure.

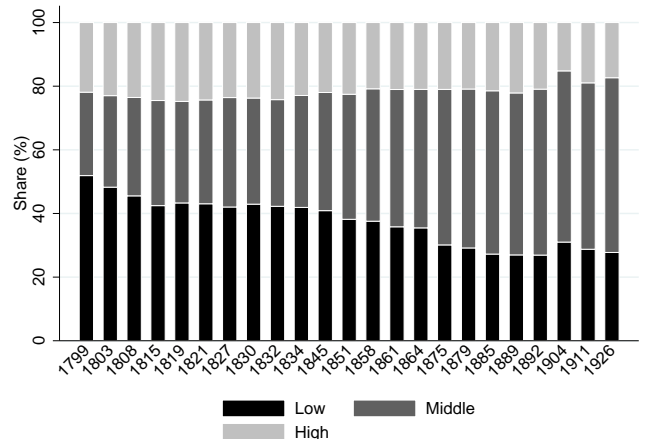

(a) SEP of C1820 citizens.

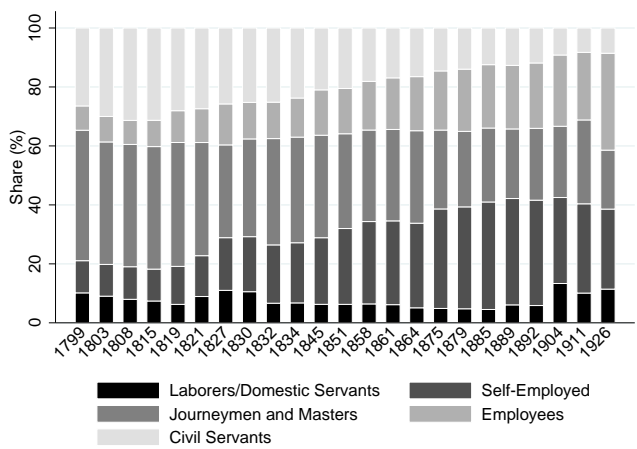

(c) Position of C1820 citizens.

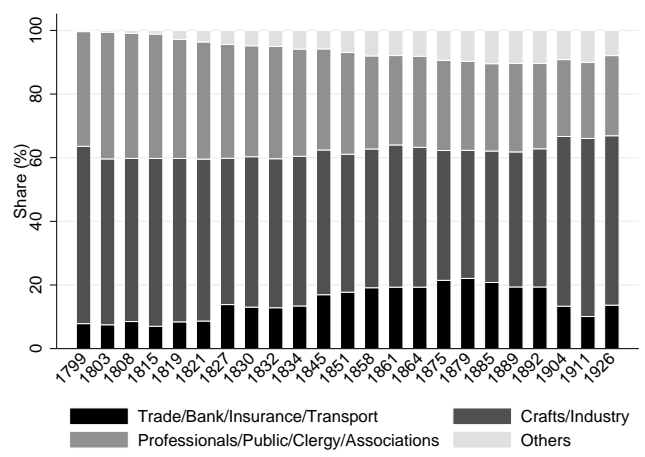

(e) Sector of C1820 citizens.

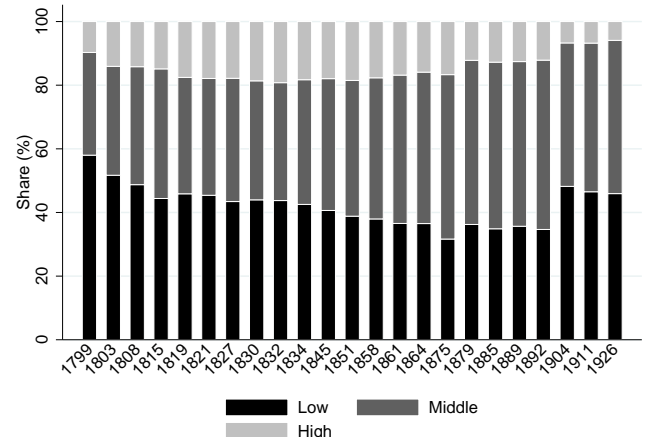

(b) SEP of ZH citizens.

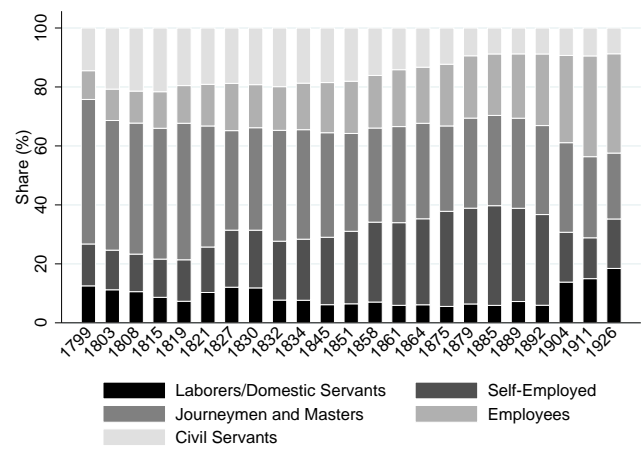

(d) Position of ZH citizens.

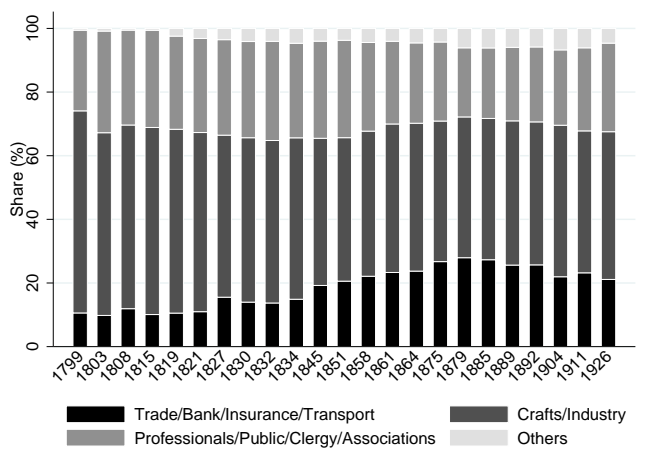

(f) Sector of ZH citizens.

Note: These figures include every citizen per year that is listed with an occupation irrespective of his age. We merged some of Schüren's (1989) categories. The combined sectors Others consist of the sectors Agriculture and Domestic Services. 


\subsection{Methods}

Mobility tables show absolute frequencies of achieving a specific occupational category conditional on the father's category. This allows to investigate the dependence of a citizen's outcome on his ancestor's in a descriptive manner and to depict the level of absolute social mobility. We use the three dimensions of Schüren (1989) as occupational categorization (SEP, position, and sector). The main analysis is based on SEP. Consider the mobility table $\mathbf{P}$, with the three SEPs low (L), middle (M), and high (H):

$$
\mathbf{P}=\left(\begin{array}{ccc}
p_{L L} & p_{L M} & p_{L H} \\
p_{M L} & p_{M M} & p_{M H} \\
p_{H L} & p_{H M} & p_{H H}
\end{array}\right)
$$

where $p_{i j}$ is the number of sons achieving SEP $j$ given their fathers belonged to category $i$. The diagonal elements $p_{i i}$ represent the number of immobile individuals, while the off-diagonal elements $p_{i j}, i \neq j$ represent mobile individuals. Upwards mobility is described in the top right corner and downwards mobility in the bottom left corner of the mobility table. In a perfectly mobile society, the entries within each column should be of equal size. Hence, one way to describe perfect mobility is a matrix of ones, $\mathbf{J}$.

We follow Altham and Ferrie (2007) and Long and Ferrie (2013) and use the metric proposed by Altham (1970) to compare the association between rows and columns across mobility tables. Consider two $3 \times 3$ mobility tables, $\mathbf{P}$ and $\mathbf{Q}$, containing the absolute frequencies $p_{i j}$ and $q_{i j}, i \in\{L, M, H\} ; j \in$ $\{L, M, H\} .^{8}$ With the SEP of fathers in the rows and the SEP of sons in the columns, the odds $p_{i j} / p_{i l}$ measure the likelihood that a son with an SEP $i$ father achieves SEP $j$ rather than SEP $l$. Odds-ratios measure the relative likelihood to end up in a specific category, and hence, inform about the association between rows and columns. For example, $\left(p_{i j} / p_{i l}\right) /\left(p_{m j} / p_{m l}\right)=$

8 For the following, see Powers and Xie (2000, p. 95-99) and Agresti (2002, p. 43-47). 
$\left(p_{i j} p_{m l}\right) /\left(p_{m j} p_{i l}\right)$ is the ratio of odds that a son achieves SEP $j$ rather than $l$, given that the father had SEP $i$ respectively $m$. In case of independence, these cross-product ratios would be equal to one.

Next, we want to compare $\mathbf{P}$ and $\mathbf{Q}$. If the row-and-column association in the two mobility tables $\mathbf{P}$ and $\mathbf{Q}$ was equal, the $\log$ differences of all crossproduct ratios would be equal to zero:

$$
\begin{aligned}
& \ln \left(\frac{p_{i j} p_{m l}}{p_{m j} p_{i l}}\right)-\ln \left(\frac{q_{i j} q_{m l}}{q_{m j} q_{i l}}\right)=\theta_{i j}+\theta_{m l}-\theta_{m j}-\theta_{i l}=0 ; \\
& \forall i \in\{L, M, H\} ; m \in\{L, M, H\} ; j=\in\{L, M, H\} ; l=\in\{L, M, H\},
\end{aligned}
$$

where $\theta_{i j}=\ln \left(p_{i j} / q_{i j}\right)$. In other words, if the log differences of the crossproduct ratios differ from zero, the row-and-column associations in the two mobility tables differ. The Altham statistic provides a method to summarize this difference:

$$
d(\mathbf{P}, \mathbf{Q})=\sqrt{\sum_{i} \sum_{j} \sum_{m} \sum_{l}\left|\theta_{i j}+\theta_{m l}-\theta_{m j}-\theta_{i l}\right|^{2}} .
$$

The Altham statistic has an attractive feature: after squaring, it is the sum of the squares of log differenced odds ratios,

$$
d(\mathbf{P}, \mathbf{Q})^{2}=\sum_{i} \sum_{j} \sum_{m} \sum_{l}\left|\theta_{i j}+\theta_{m l}-\theta_{m j}-\theta_{i l}\right|^{2}
$$

Hence, it is possible to identify those odds-ratios which contribute most to $d(\mathbf{P}, \mathbf{Q})^{2}$. This allows to detect the components that drive mobility up or down. Using the Altham statistic to compare $\mathbf{P}$ and $\mathbf{Q}$ allows to check whether the row-and-column associations between the two mobility tables differ and, thus, whether social mobility differs between the two. To evaluate which mobility table is further away from perfect mobility, an additional comparison of each table with a matrix of ones, $\mathbf{J}$, is necessary. If, for example, $d(\mathbf{P}, \mathbf{Q}) \neq 0$ and $d(\mathbf{P}, \mathbf{J})>d(\mathbf{Q}, \mathbf{J})$ the mobility table $\mathbf{P}$ is further away from perfect mobility (Long and Ferrie, 2013). 
As in Altham and Ferrie (2007) and Long and Ferrie (2013), we report the likelihood ratio statistic $G^{2}$, which follows a $\chi^{2}$-distribution (Agresti, 2002, p. 131-132). This statistic compares the likelihood of a saturated log-linear model for the frequencies with a restricted model. When comparing the matrices $\mathbf{P}$ with $\mathbf{J}$, the restricted model is the model of mutual independence, i.e. there is no interaction between the rows and columns of the contingency matrix, and hence, no relationship between the SEP of father and son. When comparing $\mathbf{P}$ with $\mathbf{Q}$, the potential interaction is not only between the rows and columns of a matrix, but also across matrices. Therefore, the restricted model in this case is a model with homogenous association, i.e. without threefactor interaction.

As an alternative measure for social mobility, we use an ordered logistic regression (ologit) model. We regress the SEP of sons on their fathers' SEP, and calculate McFadden's pseudo R-squared (e.g. Long, 1997)

$$
R^{2}=1-\frac{\ln \hat{L}\left(\text { full }_{\text {model }}\right)}{\ln \hat{L}\left(\text { baseline }_{\text {model }}\right)}
$$

where $\ln \hat{L}\left(\right.$ full $\left._{\text {model }}\right)$ is the log-likelihood of the full model including the fathers' SEP, and ln $\hat{L}$ (baseline model $)$ is the log-likelihood of the baseline model including no explanatory variables. Thus, it can be interpreted as a measure for the explanatory power of the fathers' SEP. Whenever intergenerational mobility is lower, fathers' SEP explains a larger fraction of the variation in individuals' SEP. Consequently, the pseudo R-squared is higher. In their analysis of social mobility in $20^{\text {th }}$ century Switzerland, Jann and Combet (2012) and Jann and Seiler (2014) also employ this measure and interpret it as proportional reduction of error (PRE). We follow their approach and construct confidence intervals using the bootstrap method with 1,000 replications. The measure is comparable as long as both the same SEP categorization and the same model are used. 


\section{Results}

\subsection{Average Level}

Table 2: Mobility tables.

\begin{tabular}{llrrr}
\hline \multirow{2}{*}{ Sample } & SEP Father & \multicolumn{3}{c}{ SEP Son } \\
\cline { 3 - 5 } & & Low & Middle & High \\
\hline \hline \multirow{3}{*}{ C1820 } & Middle $(2174)$ & $58.73 \%$ & $31.70 \%$ & $9.56 \%$ \\
& High $(1224)$ & $20.60 \%$ & $56.76 \%$ & $21.15 \%$ \\
& Total $(5092)$ & $33.92 \%$ & $44.66 \%$ & $21.41 \%$ \\
\hline \multirow{3}{*}{ ZH } & Low $(2241)$ & $58.14 \%$ & $36.85 \%$ & $4.99 \%$ \\
& Middle $(2512)$ & $21.05 \%$ & $62.73 \%$ & $16.20 \%$ \\
& High $(655)$ & $17.07 \%$ & $43.59 \%$ & $39.32 \%$ \\
\hline & Total $(5408)$ & $35.94 \%$ & $49.69 \%$ & $14.36 \%$ \\
\hline
\end{tabular}

Note: $C 1820$ is the sample with citizens from families holding citizenship already before 1820. $Z H$ includes all individuals spending most of their lifetime in the city of Zurich (see Section 2.1 for details). The numbers in brackets are the absolute number of observations per row. Total shows the unconditional distribution across sons' SEPs.

Table 2 displays the relative mobility tables of SEP from fathers to sons. The upper part of the table summarizes the mobility table for the C1820 sample. The high percentages on the diagonal suggest that the probability of achieving a specific SEP depended positively on the SEP of the father. Weighting the probabilities with the share of fathers per SEP shows that the majority of sons $(52.97 \%)$ held occupations with the same SEP as the occupation of their fathers. In fact, a sizable fraction of these sons had the exact same occupation as the father $(28.92 \%)$. But, at the same time, a large fraction of 
the population was occupationally mobile. ${ }^{9}$ Since there were only few high SEP jobs available, the small probability of achieving high SEP irrespective of the father's SEP is not astonishing. The mobility table of the second sample, ZH, is similar to the C1820 sample, with some exceptions: slightly more people are socially immobile $(57.99 \%),{ }^{10}$ the fraction of individuals with high SEP is lower, and, thus, the fraction of individuals with low or middle SEP is higher.

Due to the differences in the occupational structure of the two samples, it is difficult to draw conclusions regarding the mobility level from the mobility tables only. To account for the labor market structure, we subtract the unconditional probability of achieving a specific SEP from the probabilities in the transition matrix. We obtain an 'excess probability', a measure for the change of the baseline probability conditional on the father's SEP. To put it differently, the excess probability measures how much more likely (compared to the average individual) it was for a son to achieve a specific SEP conditional on the father's SEP.

The excess probabilities and the unconditional fraction of sons within each SEP in Table 3 show large positive entries on the diagonal and negative or small entries on the off-diagonal. The SEP of an individual positively depended on the SEP of its father, an interdependence which was particularly strong for low SEP suggesting high intergenerational persistence in this group. Moreover, there is a structural difference between the two samples regarding individuals with high SEP fathers: the C1820 high SEP group is more open. In this sample, the excess probabilities of achieving low or middle SEP given a high SEP father are higher and the excess probability of achieving high SEP given a high SEP father is lower.

9 As a comparison, Falcon (2012, 2013, 2016) finds that between $40 \%$ and $50 \%$ of Swiss men were socially immobile during the $20^{\text {th }}$ century. This suggests only small differences between the levels of mobility in the two centuries.

$1027.21 \%$ of the immobile sons had the same occupation as the father. 
Table 3: Excess probabilities.

\begin{tabular}{llrrr}
\hline \multirow{2}{*}{ Sample } & \multirow{2}{*}{ SEP Father } & \multicolumn{3}{c}{ SEP Son } \\
\cline { 3 - 5 } C1820 & Low & $+24.81 \mathrm{pp}$ & $-12.96 \mathrm{pp}$ & $-11.84 \mathrm{pp}$ \\
& Middle & $-11.84 \mathrm{pp}$ & $+12.09 \mathrm{pp}$ & $-0.25 \mathrm{pp}$ \\
& High & $-13.31 \mathrm{pp}$ & $-3.53 \mathrm{pp}$ & $+16.85 \mathrm{pp}$ \\
\hline \hline & Baseline & $33.92 \%$ & $44.66 \%$ & $21.41 \%$ \\
\hline \multirow{3}{*}{ ZH } & Low & $+22.20 \mathrm{pp}$ & $-12.83 \mathrm{pp}$ & $-9.36 \mathrm{pp}$ \\
& Middle & $-14.88 \mathrm{pp}$ & $+13.04 \mathrm{pp}$ & $+1.83 \mathrm{pp}$ \\
& High & $-18.86 \mathrm{pp}$ & $-6.09 \mathrm{pp}$ & $+24.96 \mathrm{pp}$ \\
\hline
\end{tabular}

Note: See Section 2.1 for a description of the samples. The number of observations within each category is the same as in Table 2. Baseline: unconditional fraction of sons within each SEP.

Tables 11, 12, 13, and 14 in the appendix contain mobility and excess probability tables for the two other dimensions of occupations, position and sector. Similar to the distribution across SEPs, the two samples differ to some extent with respect to the distribution across positions and sectors. The tables provide an alternative categorization than SEP with more and more homogeneous occupational categories. The fraction of immobile sons with respect to occupational position and sector is large (about 40\%) in both samples (Tables 11 and 12). There is more exchange between the different classes for both dimensions as compared to SEP (Tables 13 and 14), which is probably due to the increase in the number of categories. ${ }^{11}$

11 For example, The positions Self-Employed and Self-Employed Masters are very similar. Likewise, the sectors Crafts, Manufacture/Industry, and the combined sector Crafts/Cottage Industry/Industry contain very similar occupations. 


\subsection{Trend and Decomposition}

We extend the previous analysis and focus on the changes over time. We divide both of our samples into cohorts based on the sons' birth years, excluding individuals born before 1775 and after 1874 due to lack of observations. To balance cohort size, the data are grouped into ten-years bins from 1780 to 1870. ${ }^{12}$

For each cohort, we construct mobility tables comparable to Table 2. Figures 4a and $4 \mathrm{~b}$ provide one method to display these mobility tables graphically. The colored bars represent the SEP of the sons, and the letters within the bars denote the SEP of the fathers. For example, the dark colored bar labeled ' $\mathrm{M}$ ' depicts the fraction of low SEP sons with a middle SEP father. There are large fluctuations, both in the share of each SEP and transitions across SEPs. The share of high SEP sons with low SEP fathers and the share of low SEP sons with high SEP fathers decrease in both samples. Ceteris paribus, this suggests a lower level of mobility and fewer transitions between these two occupational categories. Table 10 in the appendix shows how the fractions of sons with the same SEP and the exact same occupation as their fathers changed over time within each SEP of the father. The fractions vary strongly. On average individuals with middle SEP fathers were most likely to pursue the same profession as their fathers. This result is mostly driven by merchants as roughly one third of middle SEP fathers were merchants and almost half of their sons became merchants as well.

Table 4 contains various measures based on the cohort mobility tables. For the C1820 sample, the number of observations per cohort is hump-shaped by construction. As all families having the citizenship already before 1820 are included in the sample, the birth cohorts before 1820 are entirely included. The decrease thereafter is caused by families vanishing from the sample, either by dying out or by actively giving up the citizenship. The measures $M, U$, and $D$ are based on the off-diagonals of the transition matrices. While $M$ is the share of mobile sons achieving an SEP different from their fathers', $U$ and

12 Each cohort $x$ covers the birth years $x-5, \ldots, x+4$ with $x=1780,1790, \ldots, 1870$. 
$D$ divide this fraction into upwards and downwards mobile sons. The share of mobile individuals shows a negative trend. $U$ and $D$ fluctuate strongly. The share of upwards mobile increases weakly over time, especially within the fraction of mobile individuals. We can compare our numbers to those of Falcon $(2012,2013,2016)$. Her results show that during the $20^{\text {th }}$ century upwards mobile individuals made up the vast majority of the mobile population. Thus, we provide first evidence of less upwards mobility during the $19^{\text {th }}$ century slowly approaching the level suggested by Falcon.

Following Altham and Ferrie (2007) and Long and Ferrie (2013), we compare the transition matrices of each cohort to a matrix of ones representing perfect mobility (Table 4, column "vs. Perfect"). The C1820 sample was never close to perfect mobility. The value of the Altham statistic $(d(\mathbf{P}, \mathbf{J}))$ increases over time. To judge the significance of this decreasing level of mobility, we compare every cohort's mobility table with the mobility table of the 1780 cohort (Table 4, column "vs. 1780"). The comparison reveals that mobility changed structurally over the course of the period. Combining this insight with the increasing Altham statistic, we gain further evidence for a decreasing level of social mobility.

The results for the ZH sample are slightly different. The number of observations is increasing because of population growth. As in the C1820 sample, the fraction of mobile individuals is weakly decreasing and the fraction of upwards mobile is increasing, both overall and within the mobile individuals. But there are consistently less mobile individuals than in the C1820 sample, which is in line with the results in Section 3.1. Similar to the results for the C1820 sample, mobility was never perfect, but the change in the magnitude of $d(\mathbf{P}, \mathbf{J})$ fluctuates strongly around a slightly upward sloping trend. The change compared to 1780 is slow and only weakly significant. Still, the level of mobility is lower for individuals born at the end of the $19^{\text {th }}$ century than at the end of the $18^{\text {th }}$ century. Overall, we see that there are considerable changes in the level and structure of social mobility over time. 
Figure 4: SEP distribution across cohorts.

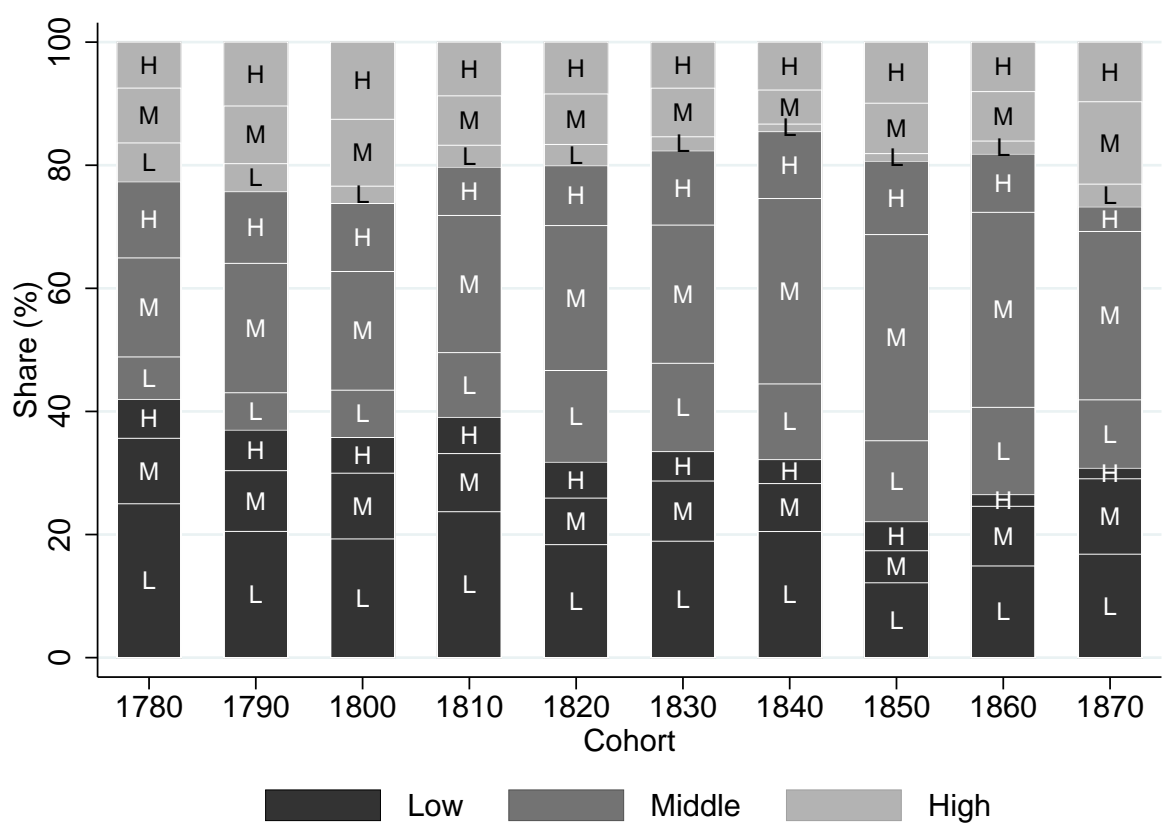

(a) C1820 sample.

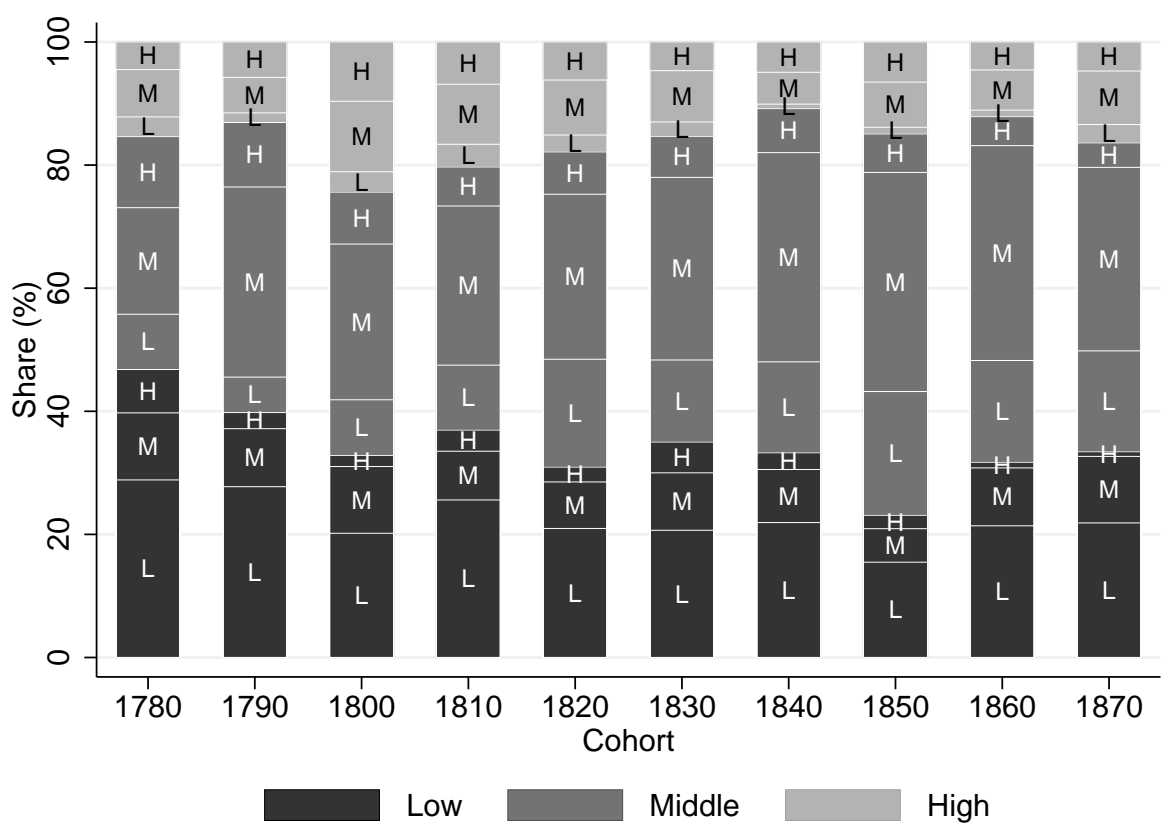

(b) ZH sample.

Note: Colored boxes: son's SEP; letters: father's SEP (L: low SEP, M: middle SEP, H: high SEP). 
Table 4: Measures of mobility for birth-cohorts 1780-1870.

\begin{tabular}{|c|c|c|c|c|c|c|c|c|c|}
\hline & \multirow{2}{*}{ Cohort } & \multirow{2}{*}{ Size } & \multirow{2}{*}{$M$} & \multirow{2}{*}{$U$} & \multirow{2}{*}{$D$} & \multicolumn{2}{|c|}{ vs. Perfect } & \multicolumn{2}{|c|}{ vs. 1780} \\
\hline & & & & & & $d(\mathbf{P}, \mathbf{J})$ & $G^{2}$ & $d(\mathbf{P}, \mathbf{Q})$ & $G^{2}$ \\
\hline \multirow{10}{*}{ 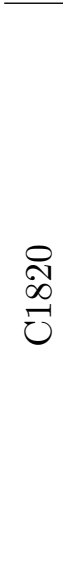 } & 1780 & 348 & 51.4 & 22.1 & 29.3 & 6.7 & $51.98^{* * *}$ & 0.0 & 0 \\
\hline & 1790 & 395 & 48.1 & 20.0 & 28.1 & 7.5 & $69.50^{* * *}$ & 2.3 & 2.76 \\
\hline & 1800 & 534 & 48.9 & 21.3 & 27.5 & 8.6 & $97.73^{* * *}$ & 4.9 & 9.43 \\
\hline & 1810 & 561 & 45.3 & 22.1 & 23.2 & 7.9 & $101.88^{* * *}$ & 5.0 & $12.10^{*}$ \\
\hline & 1820 & 463 & 49.7 & 26.6 & 23.1 & 7.1 & $58.40^{* * *}$ & 5.5 & $13.64^{* *}$ \\
\hline & 1830 & 481 & 51.1 & 24.5 & 26.6 & 8.0 & $60.53^{* * *}$ & 5.5 & $11.59^{*}$ \\
\hline & 1840 & 488 & 41.6 & 19.1 & 22.5 & 11.2 & $119.43^{* * *}$ & 7.8 & $19.92^{* * *}$ \\
\hline & 1850 & 403 & 44.4 & 22.6 & 21.8 & 10.7 & $76.28^{* * *}$ & 8.3 & $22.12^{* * *}$ \\
\hline & 1860 & 423 & 45.4 & 24.3 & 21.0 & 10.3 & $70.25^{* * *}$ & 7.1 & $16.90^{* *}$ \\
\hline & 1870 & 351 & 46.2 & 28.2 & 17.9 & 10.1 & $67.83^{* * *}$ & 7.6 & $19.38^{* * *}$ \\
\hline \multirow{10}{*}{$\stackrel{\mathbb{N}}{N}$} & 1780 & 156 & 49.4 & 19.9 & 29.5 & 6.9 & $24.84^{* * *}$ & 0.0 & 0 \\
\hline & 1790 & 191 & 35.6 & 13.1 & 22.5 & 12.5 & $74.56^{* * *}$ & 6.7 & 8.05 \\
\hline & 1800 & 332 & 44.9 & 23.8 & 21.1 & 10.8 & $77.40^{* * *}$ & 6.0 & 6.03 \\
\hline & 1810 & 379 & 41.7 & 24.0 & 17.7 & 9.2 & $92.54^{* * *}$ & 4.2 & 4.17 \\
\hline & 1820 & 291 & 46.0 & 29.2 & 16.8 & 9.5 & $51.51^{* * *}$ & 5.3 & 4.48 \\
\hline & 1830 & 300 & 45.0 & 24.0 & 21.0 & 7.9 & $45.57^{* * *}$ & 4.4 & 4.04 \\
\hline & 1840 & 406 & 39.2 & 20.7 & 18.5 & 12.8 & $95.73^{* * *}$ & 8.4 & $9.89^{*}$ \\
\hline & 1850 & 368 & 42.4 & 28.5 & 13.9 & 12.7 & $80.72^{* * *}$ & 9.0 & $12.28^{*}$ \\
\hline & 1860 & 659 & 39.2 & 24.1 & 15.0 & 14.1 & $154.17^{* * *}$ & 9.8 & $14.85^{* *}$ \\
\hline & 1870 & 805 & 43.6 & 28.1 & 15.5 & 11.6 & $143.92^{* * *}$ & 7.8 & $11.36^{*}$ \\
\hline
\end{tabular}

Note: A description of the samples can be found in Section 2.1. Size is the number of sons per cohort. $M$ is total mobility (percent off the main diagonal of the transition matrix), $U$ is the fraction of upwards mobile individuals, $D$ the fraction of downwards mobile individuals, vs. Perfect displays the results for a comparison of each cohort and a matrix of ones, $\mathbf{J}$ representing perfect mobility, vs. 1780 compares each cohort to the 1780 cohort mobility table, $\mathbf{Q} . d(\mathbf{P}, \mathbf{J})$ and $d(\mathbf{P}, \mathbf{Q})$ are the Altham statistics, the stars indicate significance levels from the $G^{2}$-test $\left({ }^{\star}: 5 \%,{ }^{\star \star}: 1 \%,{ }^{\star \star}\right.$ : $\left.0.1 \%\right)$. Degrees of freedom: 4 . 
Figure 5: Altham Statistic - Decomposition.

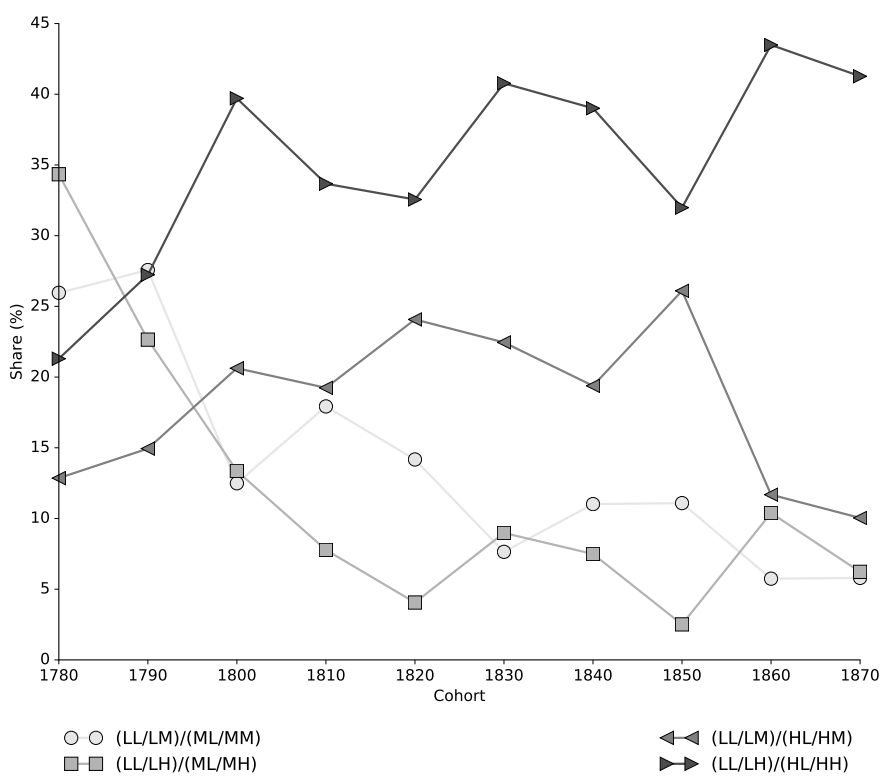

(a) C1820 sample.

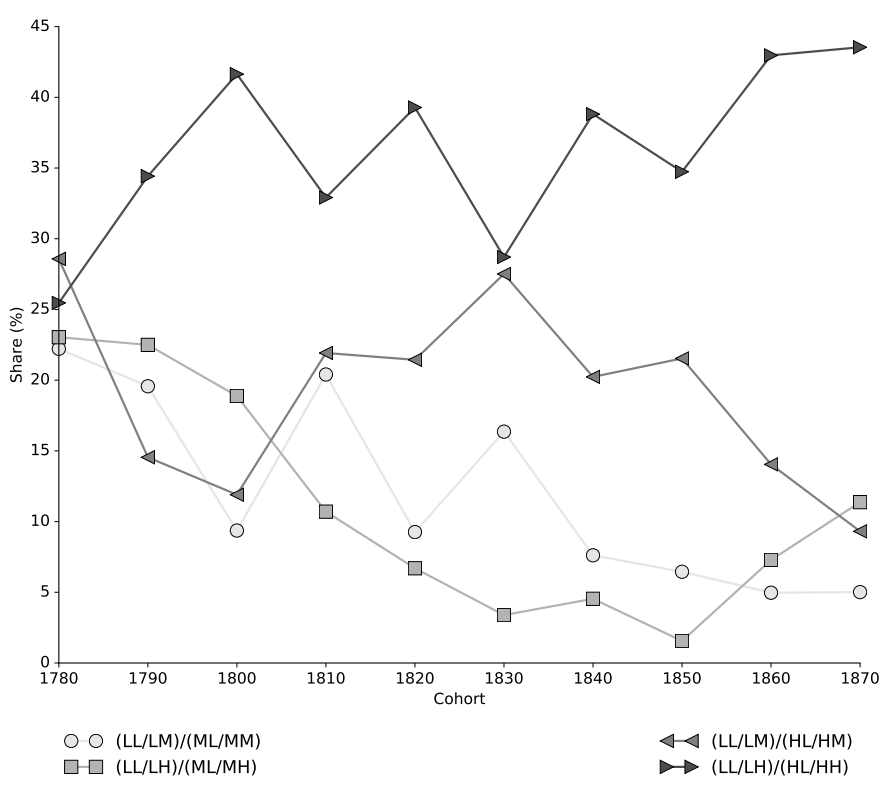

(b) ZH sample.

Note: These are the four odds ratios contributing the most to the value of the Altham statistic in the comparison of every cohort's mobility table with perfect mobility in both samples. "Share" denotes the fraction of the Altham statistic $d(\mathbf{P}, \mathbf{J})$ attributable to the corresponding odds ratios. 
Figure 6: Altham statistic and PRE across cohorts.

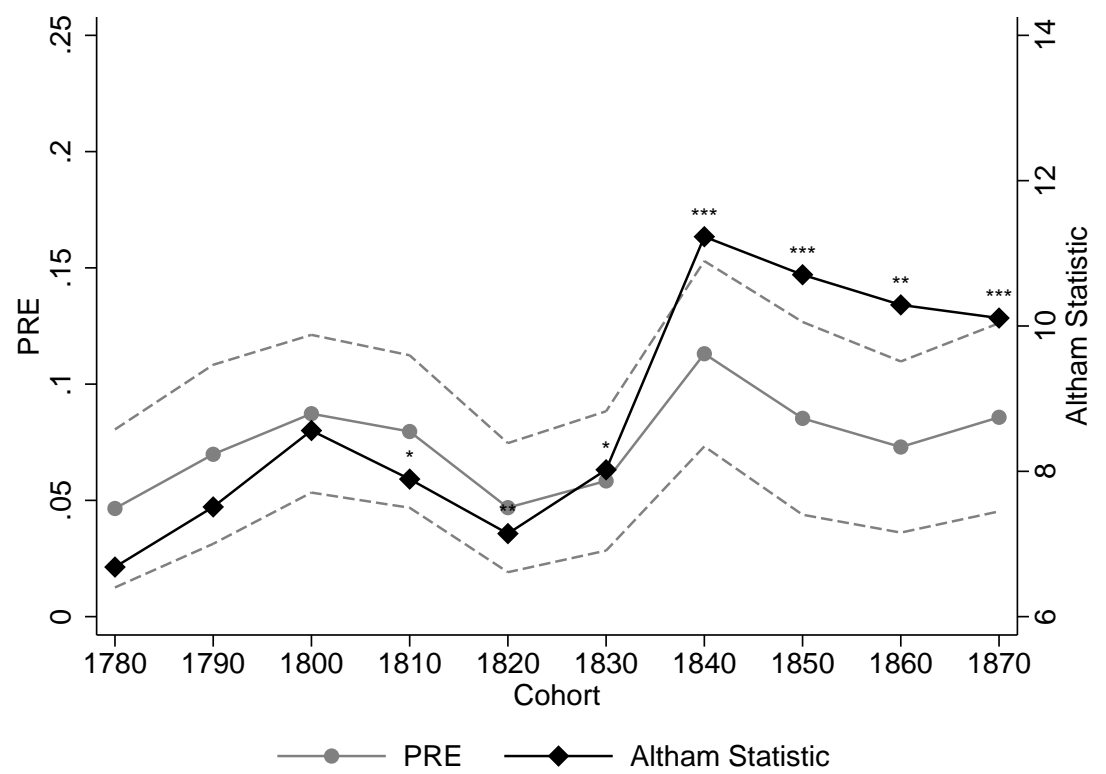

(a) C1820 sample.

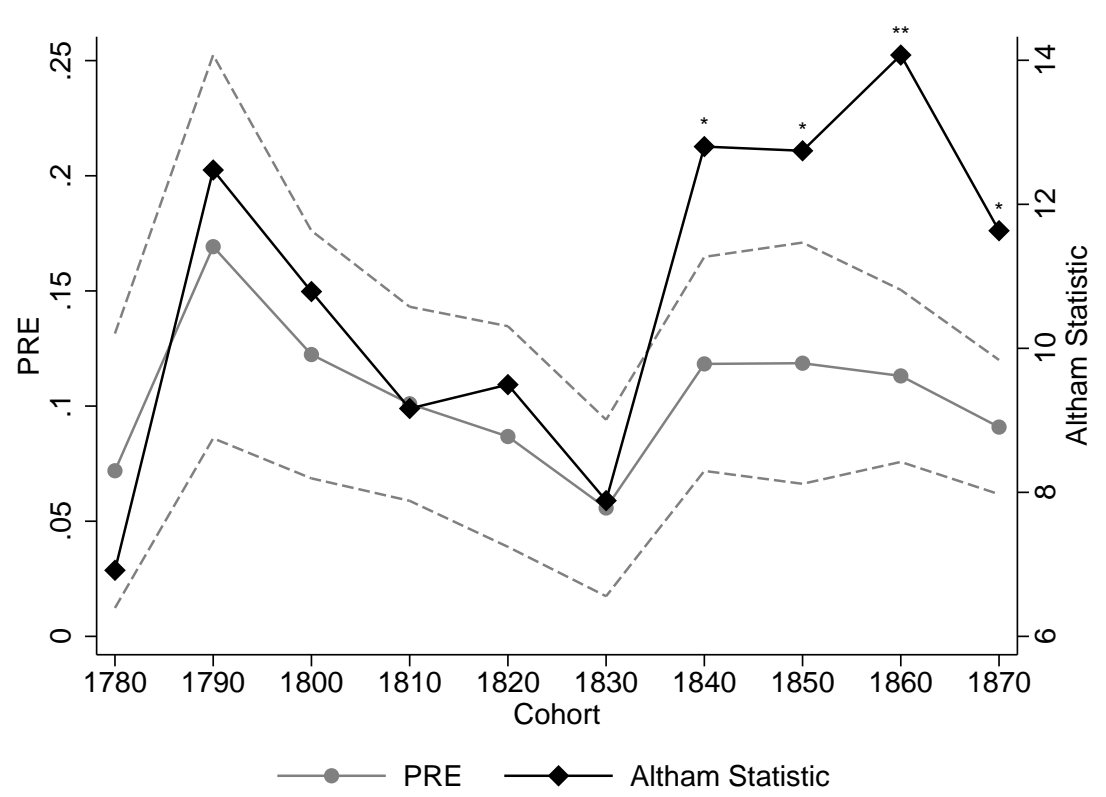

(b) ZH sample.

Note: The values of the Altham statistic come from the comparison of the cohort mobility tables with perfect mobility. The stars indicating significance are from the $G^{2}$ statistic of the comparison of every cohort's mobility table with the mobility table of the 1780 cohort. The higher both measures the lower is mobility. 
The decomposition of the Altham statistic (Section 2.2) identifies the part of the mobility table responsible for the level of mobility and its change. The contribution of the four most important (of nine) odds ratios over the cohorts are displayed in Figures 5a and 5b. Figure 5a shows that the dominating odds ratio in the $\mathrm{C} 1820$ sample is $(L L / L H) /(H L / H H) .{ }^{13}$ The numerator is the odds of the son achieving a low SEP as opposed to a high SEP, given a low SEP father. The denominator is the odds of the son achieving a low SEP as opposed to a high SEP, given a high SEP father. The importance of this odds ratio increases strongly over time, decreasing the impact of the other odds ratios. This result provides evidence on major social barriers between the two tailing SEPs, which is in line with the picture of low and decreasing transition between these two SEPs (Figure 4a). Interestingly, all of the four most important odds ratios include the transition from low to low SEP, which suggests that it was particularly unlikely to transition out of low SEP. For the ZH sample, the results are qualitatively the same (Figure 5b).

The literature evolving around the seminal paper of Becker and Tomes (1979) provides a framework to think about potential explanations for the intergenerational persistence. First of all, there are comparatively poor individuals in the low SEP category, and annual income and wealth are clearly lower for low SEP individuals (Section 2, Figure 2). The distribution of low SEP individuals across positions and sectors also differs strongly from middle and high SEP individuals (Appendix, Table 6). Hence, a poverty trap in the sense of e.g. Horrell et al. (2001) could be at work. This means that low SEP fathers are not able to invest enough in their sons' human capital to help them advance socioeconomically. On the other hand, the vast majority of low SEP individuals are craftsmen such as locksmiths, carpenters, and bakers (Appendix, Table 5). The decision of the parents to invest in their sons' human capital specific to the occupation of the father could also play a role for the observed persistence. Similarly, the endowment of the son with

13 In the notation of Section $2.2 \ln (L L)$ corresponds to $\theta_{L L}$. $\mathbf{P}$ would be equivalent to every cohort's transition matrix and $\mathbf{Q}=\mathbf{J}$, a matrix of ones representing perfect mobility. 
inherited occupation-specific physical capital may be of larger importance for occupations corresponding to low SEP. Finally, intergenerational persistence of low SEP could partly be driven by the control of access to the labor market imposed by the guilds.

For a long time, only guild-masters were allowed to employ and train journeymen and apprentices. This regulation was abolished by the liberal forces taking over in Zurich in 1830. The craft training of apprentices was partly transferred to the newly established vocational schools. Nevertheless, most of the training still remained within manufacturing and industrial businesses. Guilds remained important network clubs and provided social services to their members. Consequently, low SEP fathers being a guild member could facilitate the entry of their sons into the same or a similar craft (Fritzsche and Lemmenmeier, 1994, p. 74-79, 128-145).

All of the mobility measures based on mobility tables suggest that the level of mobility was weakly decreasing in the $19^{\text {th }}$ century. This holds for both the $\mathrm{C} 1820$ sample and the $\mathrm{ZH}$ sample. As an alternative, we move away from mobility tables and use a different measure to quantify mobility for the remainder of this section. The pseudo R-squared generated by an ologit regression of sons' SEP on their fathers' SEP provides a different view on the intergenerational link (Section 2.2). As in Jann and Combet (2012) and Jann and Seiler (2014), we call this measure in our application proportional reduction of error (PRE, Figures 6a and 6b left vertical axis). As a comparison we include the information from the Altham statistic, $d(\mathbf{P}, \mathbf{Q})$ (column "vs. Perfect", Table 4), with the stars indicating significance (column "vs. 1780", Table 4) into the Figures 6a and 6b (right vertical axis).

At a first glance, the PRE pattern and the Altham statistic are quite similar. We see simultaneous fluctuations over time featured by a trend away from perfect mobility. However, the bandwidth of the confidence interval around the PRE suggests that the change is not statistically significant. Even though the PRE patterns and the Altham statistic appear to overlap to some extent, PRE suggests no significant decrease in the level of mobility over the course of the $19^{\text {th }}$ century. Both samples exhibit stronger deviations of the two 
measures' trend in the second half of the $19^{\text {th }}$ century. Although there are differences in calculating PRE, our results are in the same order of magnitude as the ones for the $20^{\text {th }}$ century in Jann and Combet (2012) and Jann and Seiler (2014). ${ }^{14}$

\section{Conclusion}

$19^{\text {th }}$ century Zurich was subject to important structural changes. These changes encompassed institutional advances on federal, cantonal, and municipal level, unprecedented population growth, industrialization and the development of the banking sector, the foundation of the universities, and the development of a railway system with Zurich as one of its hubs. Consequently, one might expect social mobility to be increasing during this time period, especially since industrialization generated new opportunities (Kury, 2012), but also because of the political climate (Behrens, 2015; Illi and König, 2017).

Despite the expectation of increasing mobility, we find a weakly decreasing level of mobility for citizens born in the period 1780 to 1870 . The results are robust with respect to the focus on either citizens originating in families already present in 1820, or citizens living in Zurich for a considerable part of their lives. Upward and downward mobility were about equal. The decomposition of the Altham statistic allows to identify the main force behind these phenomena: both level and change in mobility were driven by intergenerational persistence of occupations with low socioeconomic position. Potential candidates to explain this persistence are a poverty-trap mechanism, labormarket imperfections due to guild regulations, or an inheritance mechanism specific to low socioeconomic positions. We still observe changes in the labor market structure featuring a transition towards the banking and transport

14 Jann and Seiler (2014) use a multinomial logistic regression model and have a different categorization of occupations. Especially the latter difference exacerbates a comparison. 
sector and an increasing share of citizens with middle socioeconomic position, but these changes are not accompanied by increasing social mobility.

Acknowledgements We would like to thank Pietro Biroli, Martin Brown, Gregory Clark, Neil Cummins, David Dorn, Sandro Favre, Luisa Gagliardi, Mikael Lindahl, Jim Malley, Isabel Martínez, Harald Mayr, Carolyn Moehling, Tobias Renkin, Stefanie Schurer, Hannes Schwandt, Gabi Wüthrich, Josef Zweimüller, and the participants of the SSES Annual Congresses 2016 and 2017, the FRESH Meeting 2016, the ZWE 2016, the Annual Conference of the ESPE 2017, the World Congress of Cliometrics 2017, the EEA/ESEM 2017, the EHES Conference 2017, the EALE Conference 2017, and the Empirical Micro Doctoral Seminar at the UZH for helpful discussions and comments on earlier versions of the paper. We also thank Andrin Good, Luca Hänni, Irina Martin, Dario Messi, and Marc Pfister for reliable research assistance.

Funding information The data collection was supported by the Richard Büchner Stiftung. 


\section{References}

Acemoglu, D., Egorov, G., and Sonin, K. (2016). Social Mobility and Stability of Democracy: Re-Evaluating De Tocqueville. NBER Working Paper 22174 .

Agresti, A. (2002). Categorical Data Analysis. John Wiley \& Sons, Hoboken, New Jersey.

Altham, P. M. (1970). The Measurement of Association of Rows and Columns for an $\mathrm{r} \times \mathrm{s}$ Contingency Table. Journal of the Royal Statistical Society. Series B (Methodological), 32 (1):63-73.

Altham, P. M. and Ferrie, J. P. (2007). Comparing Contingency Tables Tools for Analyzing Data from Two Groups Cross-Classified by Two Characteristics. Historical Methods: A Journal of Quantitative and Interdisciplinary History, 40(1):3-16.

Barone, G. and Mocetti, S. (2016). Intergenerational Mobility in the Very Long Run: Florence 1427-2011. Working Paper 1060, Bank of Italy, https://ssrn.com/abstract $=2856359$.

Becker, G. S. and Tomes, N. (1979). An Equilibrium Theory of the Distribution of Income and Intergenerational Mobility. Journal of Political Economy, 87(6):1153-1189.

Behrens, N. (2015). Zürich (Gemeinde) - Die politisch-administrative Enwicklung im 19. und 20. Jahrhundert - Gesellschaft, Wirtschaft und Kultur im 19. und 20. Jahrhundert. Historisches Lexikon der Schweiz (HLS), 25.1.2015, http://www.hls-dhs-dss.ch/textes/d/D171.php.

Black, S. E. and Devereux, P. (2011). Recent developments in intergenerational mobility. In Ashenfelter, O. and Card, D., editors, Handbook of Labor Economics, volume 4, chapter 16, pages 1487-1541. Elsevier, Amsterdam, Boston, Heidelberg, London, New York, Oxford, Paris, San Diego, San Francisco, Singapore, Sydney, Tokyo. 
Blau, P. and Duncan, O. D. (1967). The American Occupational Structure. John Wiley \& Sons, New York.

Clark, G. (2014). The Son Also Rises: Surnames and the History of Social Mobility. Princeton University Press, Princeton.

Clark, G. and Cummins, N. (2014). Inequality and Social Mobility in the Era of the Industrial Revolution. In Floud, R., Humphries, J., and Johnson, P., editors, The Cambridge Economic History of Modern Britain, volume 1, chapter 7, pages 211-236. Cambridge University Press, Cambridge.

Clark, G. and Cummins, N. (2015). Intergenerational Wealth Mobility in England, 1858-2012: Surnames and Social Mobility. The Economic Journal, 125:61-85.

Clark, G., Cummins, N., Hao, Y., and Vidal, D. D. (2015). Surnames: A New Source for the History of Social Mobility. Explorations in Economic History, 55:3-24.

de Tocqueville, A. (2004). Democracy in America. Bantam, New York.

Dribe, M. and Helgertz, J. (2016). The Lasting Impact of Grandfathers: Class, Occupational Status, and Earnings over Three Generations in Sweden 1815-2011. The Journal of Economic History, 76(4):969-1000.

Dribe, M., Helgertz, J., and Van de Putte, B. (2015). Did Social Mobility increase during the Industrialization Process? A Micro-Level Study of a Transforming Community in Southern Sweden 1828-1968. Research in Social Stratification and Mobility, 41:25-39.

Dribe, M. and Svensson, P. (2008). Social Mobility in Nineteenth Century Rural Sweden - A Micro Level Analysis. Scandinavian Economic History Review, 56(2):122-141.

Falcon, J. (2012). Temporal Trends in Intergenerational Social Mobility in Switzerland: A Cohort Study of Men and Women Born Between 1912 and 1974. Swiss Journal of Sociology, 38(2):153-175. 
Falcon, J. (2013). Social Mobility in 20th Century Switzerland.

Falcon, J. (2016). Soziale Mobilität in der Schweiz im 20. Jahrhundert: zwischen Demokratisierung der Bildung und Fortbestand der Klassenungleichheiten. Social Change.

Fritzsche, B. and Lemmenmeier, M. (1994). Die revolutionäre Umgestaltung von Wirtschaft, Gesellschaft und Staat 1780-1880. In Geschichte des Kantons Zürich. 19. und 20. Jahrhundert, volume 3, pages 20-157. Werd, Zürich.

Gordon, B. (2002). The Swiss Reformation. Manchester University Press, Manchester, New York.

Hofmeister, W. (1813). Etat der Gemeinds-Bürgerschaft der Stadt Zürich. Locher, Joh. Caspar.

Horrell, S., Humphries, J., and Voth, H.-J. (2001). Destined for Deprivation: Human Capital Formation and Intergenerational Poverty in NineteenthCentury England. Explorations in Economic History, 38(3):339-365.

Humphries, J. (2010). Childhood and Child Labour in the British Industrial Revolution. Cambridge University Press, Cambridge, New York.

Illi, M. and König, M. (2017). Zürich (Kanton) - Der Zürcher Staat im 19. und 20. Jahrhundert - Gesellschaft, Wirtschaft und Kultur im 19. und 20. Jahrhundert. Historisches Lexikon der Schweiz (HLS), 24.8.2017, http://www.hls-dhs-dss.ch/textes/d/D7381.php.

Jann, B. and Combet, B. (2012). Zur Entwicklung der intergenerationalen Mobilität in der Schweiz. Swiss Journal of Sociology, 38:177-199.

Jann, B. and Seiler, S. (2014). A New Methodological Approach for studying Intergenerational Mobility with an Application to Swiss Data. Working Paper 5, University of Bern Social Sciences.

Kley, A. (2011). Bundesverfassung (BV). Historisches Lexikon der Schweiz (HLS), 3.5.2011, http://www.hls-dhs-dss.ch/textes/d/D9811.php. 
Kury, P. (2012). Soziale Mobilität. Historisches Lexikon der Schweiz (HLS), 4.1.2012, http://www.hls-dhs-dss.ch/textes/d/D15995.php.

Landes, D. S. (2003). The Unbound Prometheus. Technological Change and Industrial Development in Western Europe from 1750 to the Present. Cambridge University Press, Cambridge, 2 edition.

Lindahl, M., Palme, M., Sandgren Massih, S., and Sjögren, A. (2015). LongTerm Intergenerational Persistence of Human Capital: An Empirical Analysis of Four Generations. Journal of Human Resources, 50(1):1-33.

Long, J. (2013). The Surprising Social Mobility of Victorian Britain. European Review of Economic History, 17(1):1-23.

Long, J. and Ferrie, J. P. (2013). Intergenerational Occupational Mobility in Great Britain and the United States since 1850. The American Economic Review, 103(4):1109-1137.

Long, J. S. (1997). Regression Models for Categorical and Limited Dependent Variables. SAGE Publications.

Olivetti, C. and Paserman, M. D. (2015). In the Name of the Son (and the Daughter): Intergenerational Mobility in the United States, 1850-1940. The American Economic Review, 105(8):2695-2724.

Piketty, T. (2014). Capital in the 21st Century. Harvard University Press, Cambridge, Mass., London.

Powers, D. A. and Xie, Y. (2000). Statistical Methods for Categorical Data Analysis. Academic Press, San Diego, London.

Schüren, R. (1989). Soziale Mobilität. Muster, Veränderungen und Bedingungen im 19. Und 20. Jahrhundert. Scripta Mercaturae Verlag, St. Katharinen.

Solon, G. (2015). What do we know so far about multigenerational mobility? NBER Working Paper 21053. 
Veyrassat, B. (2012). Wirtschaft und Gesellschaft an der Wende zum 20. Jahrhundert. In Halbeisen, P., Müller, M., and Veyrassat, B., editors, Wirtschaftsgeschichte der Schweiz im 20. Jahrhundert, pages 984-1075. Schwabe Verlag, Basel.

Wirth, M., editor (1871-1875). Allgemeine Beschreibung und Statistik der Schweiz. Im Verein mit einer Anzahl schweizerischer Gelehrter und Staatsmänner, Zürich. Orell Füssli \& Comp. 


\section{Appendix}

Table 5: Categories in Schüren (1989).

\begin{tabular}{|c|c|c|}
\hline Dimension & Classes & \\
\hline \multirow{6}{*}{ SEP } & Lowest & \multirow{3}{*}{ Low } \\
\hline & Medium Low & \\
\hline & Upper Low & \\
\hline & Lower Middle & \multirow{2}{*}{ Middle } \\
\hline & Upper Middle & \\
\hline & High & High \\
\hline \multirow{7}{*}{ Position } & \multicolumn{2}{|l|}{ Laborers } \\
\hline & \multicolumn{2}{|c|}{ Domestic Servants } \\
\hline & \multicolumn{2}{|l|}{ Self-Employed } \\
\hline & \multicolumn{2}{|c|}{ Journeymen and Masters } \\
\hline & \multicolumn{2}{|c|}{ Self-Employed Masters } \\
\hline & \multicolumn{2}{|l|}{ Employees } \\
\hline & \multicolumn{2}{|l|}{ Civil Servants } \\
\hline & \multicolumn{2}{|l|}{ Agriculture } \\
\hline & \multicolumn{2}{|c|}{ Domestic Services } \\
\hline & \multicolumn{2}{|l|}{ Crafts } \\
\hline & \multicolumn{2}{|c|}{ Cottage Industry } \\
\hline Sector & \multicolumn{2}{|c|}{ Manufacture/Industry } \\
\hline & \multicolumn{2}{|c|}{ Crafts/Cottage Industry/Industry } \\
\hline & \multicolumn{2}{|c|}{ Trade/Bank/Insurance/Transport } \\
\hline & \multicolumn{2}{|l|}{ Professionals } \\
\hline & \multicolumn{2}{|c|}{ Public/Clergy/Associations } \\
\hline
\end{tabular}

Note: We merge the original SEP-categories of Schüren (1989) into three categories. The most frequent occupations in the low SEP category are locksmiths, mechanics, carpenters, bakers, and shoemakers. The middle SEP category is dominated by merchants, followed by engineers, architects, teachers, and innkeepers. In the high SEP category, we have priests, physicians, professors, chemists, and lawyers. 
Table 6: Distribution of each SEP across Positions and Sectors.

\begin{tabular}{|c|c|c|c|c|}
\hline & \multirow{2}{*}{ Category } & \multicolumn{3}{|c|}{ SEP } \\
\hline & & Low & Middle & High \\
\hline \multirow{7}{*}{ Position } & Laborers & $20.66 \%$ & $0.34 \%$ & $0 \%$ \\
\hline & Domestic Servants & $0.86 \%$ & $0 \%$ & $0 \%$ \\
\hline & Self-Employed & $1.26 \%$ & $30 \%$ & $26.88 \%$ \\
\hline & Journeymen and Masters & $64.78 \%$ & $1.16 \%$ & $0 \%$ \\
\hline & Self-Employed Masters & $0 \%$ & $0.18 \%$ & $0 \%$ \\
\hline & Employees & $9.75 \%$ & $32 \%$ & $9.39 \%$ \\
\hline & Civil Servants & $1.07 \%$ & $8.22 \%$ & $51.65 \%$ \\
\hline \multirow{9}{*}{ Sector } & Agriculture & $\overline{0 .} \overline{\overline{6}} \overline{\mathrm{C}} \overline{\mathrm{C}}$ & $0 . \overline{21 \%}$ & $2.01 \%$ \\
\hline & Domestic Services & $3.44 \%$ & $4.10 \%$ & $0.04 \%$ \\
\hline & Crafts & $2.84 \%$ & $2.48 \%$ & $0 \%$ \\
\hline & Cottage Industry & $0 \%$ & $0 \%$ & $0 \%$ \\
\hline & Manufacture/Industry & $6.44 \%$ & $11.02 \%$ & $12.34 \%$ \\
\hline & Crafts/Cottage Industry/Industry & $69.65 \%$ & $1.37 \%$ & $0 \%$ \\
\hline & Trade/Bank/Insurance/Transport & $3.87 \%$ & $33.15 \%$ & $2.86 \%$ \\
\hline & Professionals & $0 \%$ & $6.89 \%$ & $17.35 \%$ \\
\hline & Public/Clergy/Associations & $10.46 \%$ & $12.67 \%$ & $53.31 \%$ \\
\hline \multicolumn{2}{|c|}{ Number of Observations } & 7101 & 8055 & 2411 \\
\hline
\end{tabular}

Note: This is the entire data set as in Table 7. The percentages show the distribution within each dimension (Position and Sector). 
Table 7: Descriptive statistics (entire data set).

\begin{tabular}{lr}
\hline Characteristic & Average/Share \\
\hline \hline Low SEP & $40.42 \%$ \\
Middle SEP & $45.85 \%$ \\
High SEP & $13.72 \%$ \\
Age at observed SEP & 37.96 \\
Number of Observations & 17567 \\
\hline
\end{tabular}

Note: We dropped all individuals without occupation (500 observations) and farmers (402 observations). 
Table 8: Number of Sons.

\begin{tabular}{|c|c|c|c|c|c|c|c|}
\hline \multirow{3}{*}{ Sample } & \multirow{3}{*}{ Number of Sons } & \multicolumn{6}{|c|}{ SEP Father } \\
\hline & & \multicolumn{2}{|c|}{ Low } & \multicolumn{2}{|c|}{ Middle } & \multicolumn{2}{|c|}{ High } \\
\hline & & $\mathrm{Obs}$ & Age & Obs & Age & $\mathrm{Obs}$ & Age \\
\hline \multirow{8}{*}{ C1820 } & 1 & 479 & 32.5 & 552 & 33.7 & 271 & 34.4 \\
\hline & 2 & 264 & 31.2 & 364 & 31.2 & 175 & 32.5 \\
\hline & 3 & 132 & 29.8 & 149 & 31.8 & 99 & 32.2 \\
\hline & 4 & 37 & 29.0 & 69 & 29.6 & 47 & 30.7 \\
\hline & 5 & 20 & 28.0 & 21 & 27.4 & 16 & 32.7 \\
\hline & 6 & 6 & 28.5 & 11 & 27.2 & 5 & 29.8 \\
\hline & 7 & 1 & 28.0 & 0 & & 1 & 28.0 \\
\hline & Average & 1.80 & 31.5 & 1.86 & 32.3 & 1.99 & 33.1 \\
\hline \multirow{8}{*}{$\mathrm{ZH}$} & 1 & 903 & 32.5 & 1004 & 32.9 & 242 & 34.4 \\
\hline & 2 & 387 & 31.4 & 434 & 30.9 & 115 & 32.1 \\
\hline & 3 & 128 & 29.3 & 137 & 30.5 & 39 & 32.3 \\
\hline & 4 & 31 & 27.9 & 40 & 29.3 & 15 & 32.9 \\
\hline & 5 & 10 & 28.0 & 10 & 28.4 & 0 & \\
\hline & 6 & 1 & 33.0 & 2 & 25.5 & 0 & \\
\hline & 7 & 0 & & 1 & 33.0 & 1 & 34.0 \\
\hline & Average & 1.53 & 31.8 & 1.54 & 32.0 & 1.59 & 33.5 \\
\hline
\end{tabular}

Note: Obs is the number of fathers per SEP and number of sons. Age is the average age at birth of the first son. 
Table 9: Number of Sons over Time.

\begin{tabular}{|c|c|c|c|c|c|c|c|c|c|c|}
\hline \multirow{3}{*}{ Sample } & \multirow{3}{*}{ Year } & \multicolumn{9}{|c|}{ SEP Father } \\
\hline & & \multicolumn{3}{|c|}{ Low } & \multicolumn{3}{|c|}{ Middle } & \multicolumn{3}{|c|}{ High } \\
\hline & & Obs & Age & NoS & Obs & Age & NoS & $\mathrm{Obs}$ & Age & $\mathrm{NoS}$ \\
\hline \multirow{4}{*}{ C1820 } & 1750 & 117 & 32.1 & 1.84 & 131 & 32.0 & 2.09 & 96 & 33.7 & 2.28 \\
\hline & 1775 & 262 & 31.9 & 1.81 & 269 & 31.3 & 1.93 & 151 & 32.2 & 2.13 \\
\hline & 1800 & 209 & 31.0 & 1.77 & 260 & 32.5 & 1.93 & 144 & 33.2 & 1.97 \\
\hline & 1825 & 144 & 31.7 & 1.85 & 255 & 33.4 & 1.76 & 97 & 32.5 & 2.08 \\
\hline \multirow{4}{*}{$\mathrm{ZH}$} & 1750 & 98 & 33.1 & 1.54 & 108 & 32.7 & 1.79 & 54 & 33.5 & 1.69 \\
\hline & 1775 & 203 & 32.1 & 1.63 & 225 & 32.1 & 1.65 & 85 & 32.7 & 1.78 \\
\hline & 1800 & 192 & 32.0 & 1.53 & 240 & 32.0 & 1.66 & 89 & 33.6 & 1.47 \\
\hline & 1825 & 361 & 33.5 & 1.55 & 471 & 33.5 & 1.51 & 101 & 34.3 & 1.68 \\
\hline
\end{tabular}

Note: Obs is the number of fathers per SEP and cohort. Age is the average age at birth of the first son. NoS is the average number of sons. 


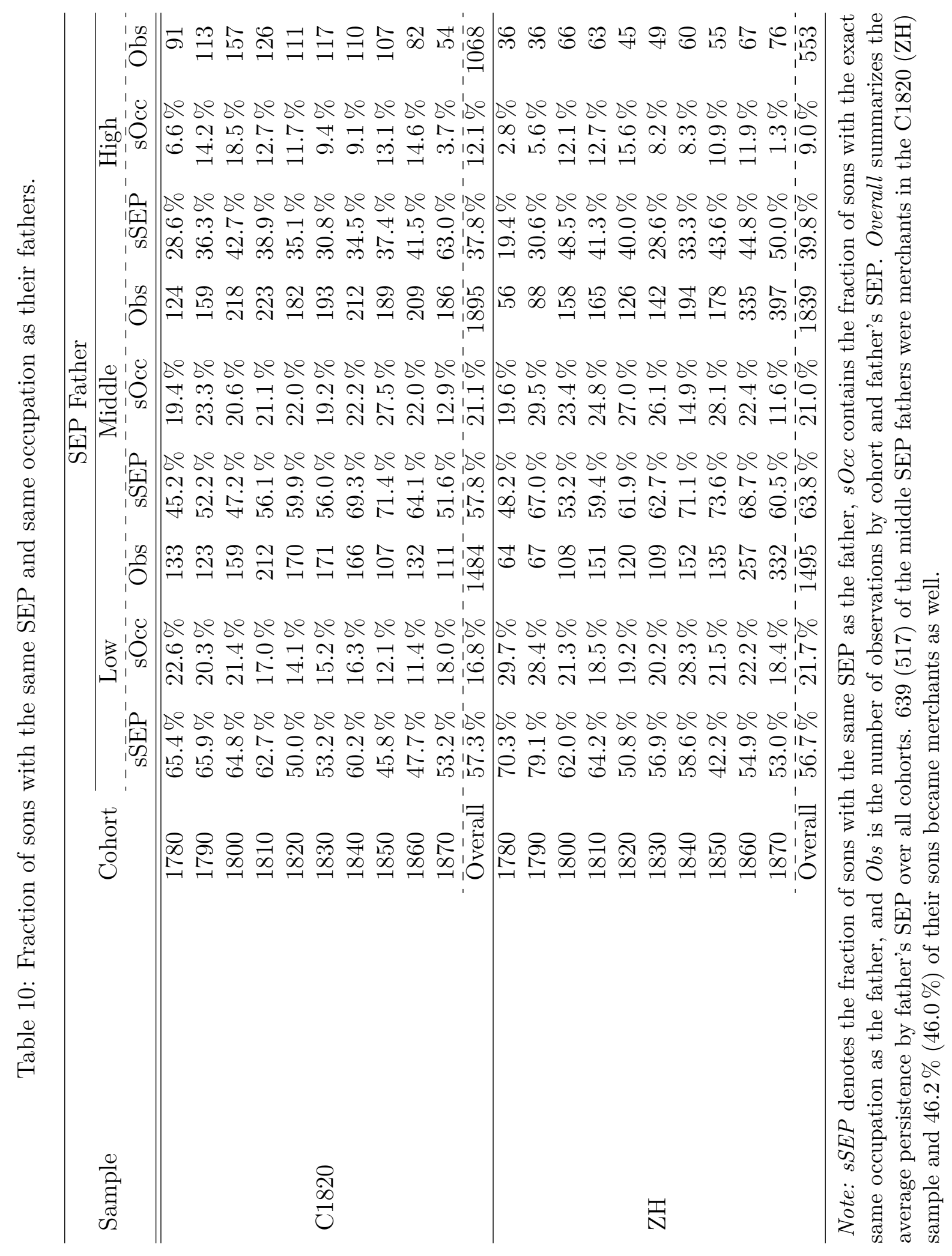




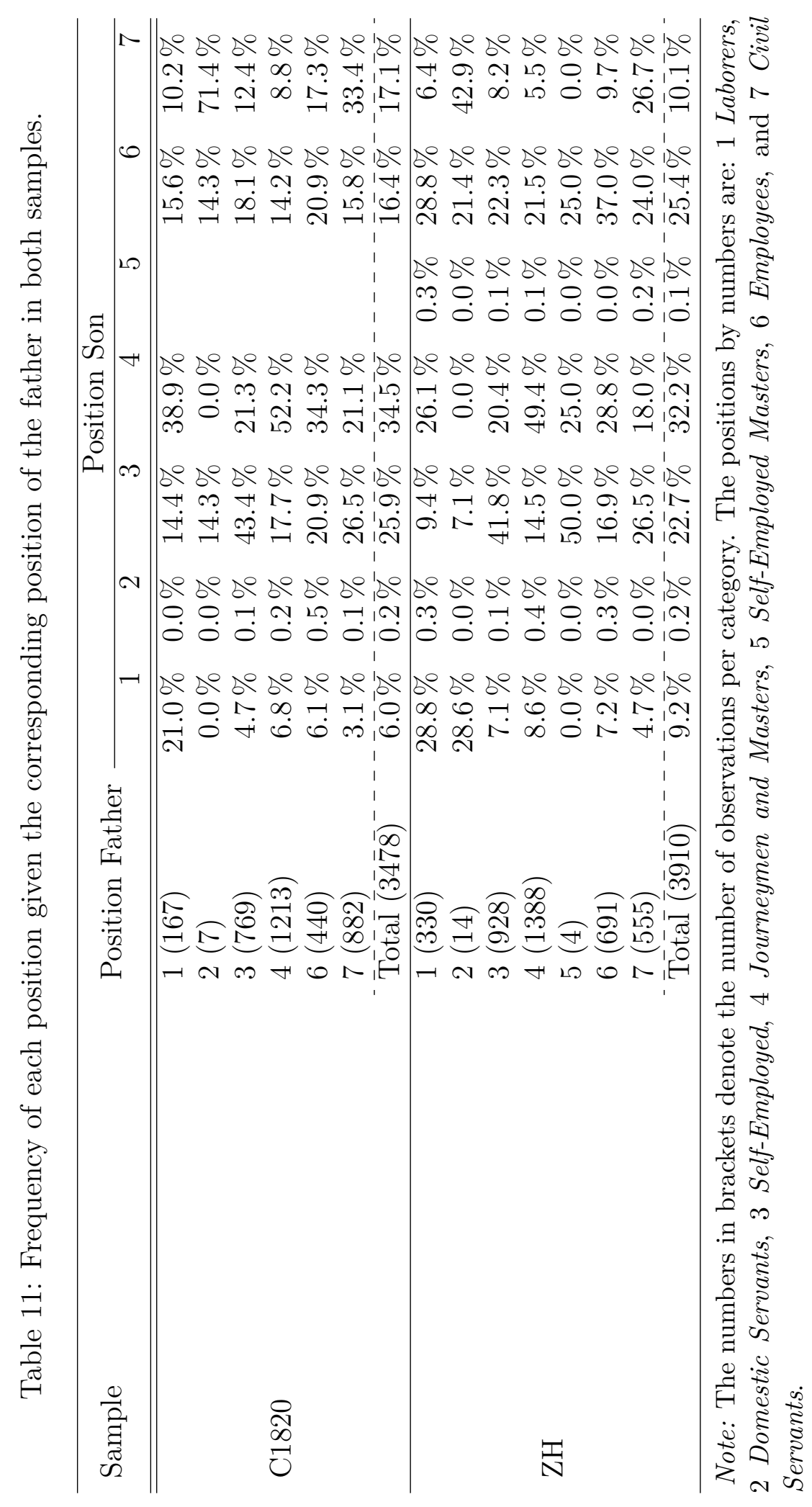




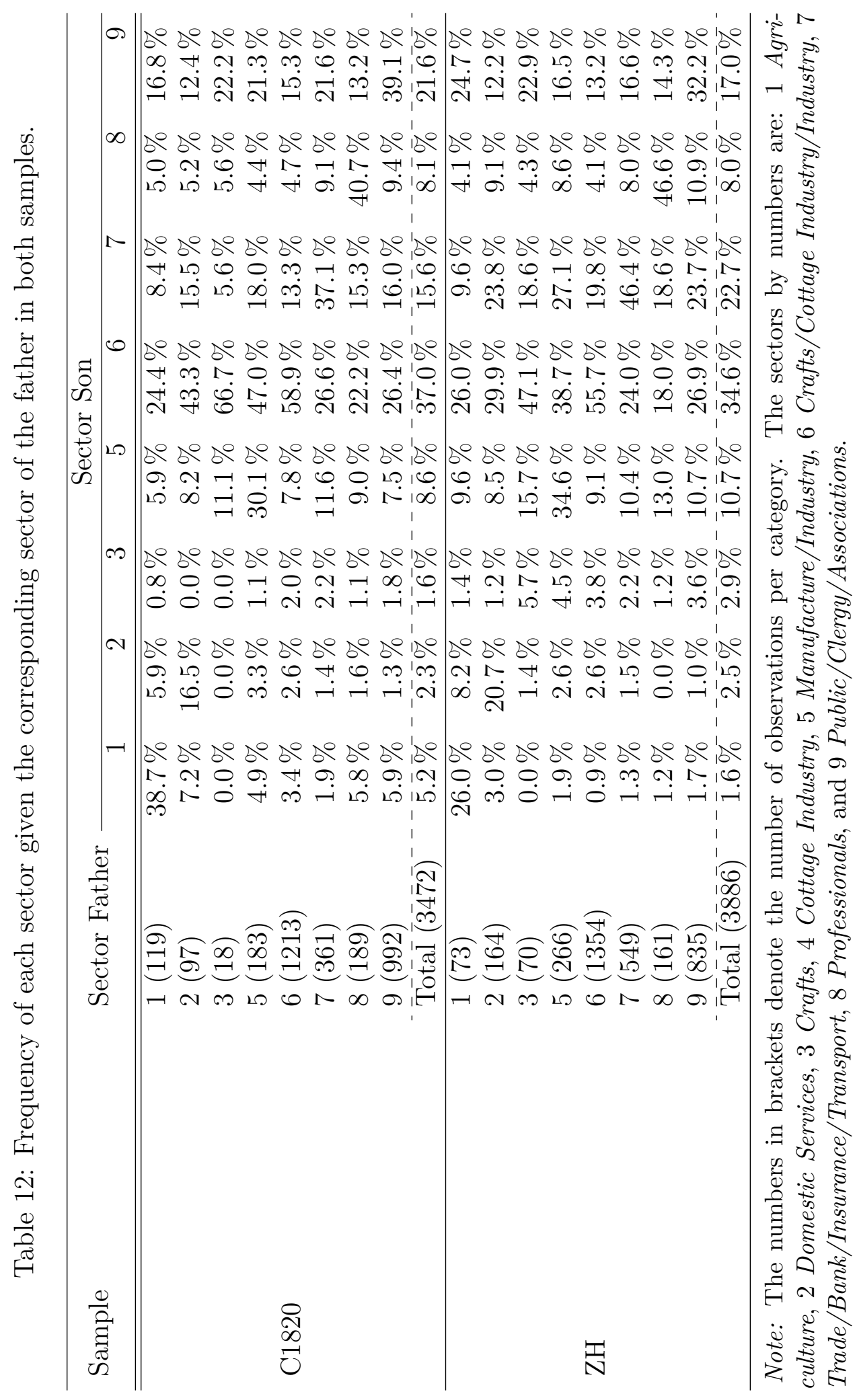




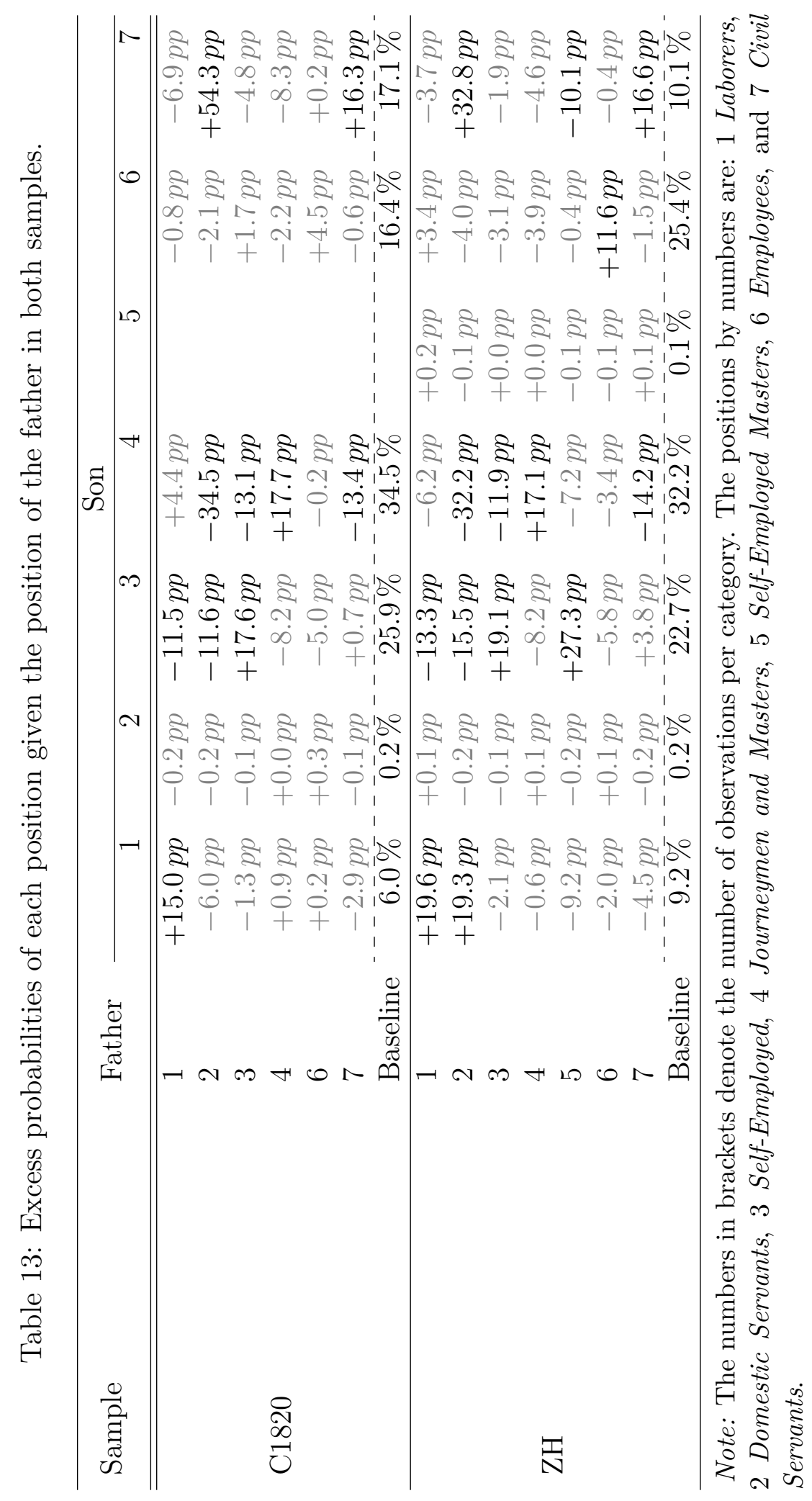




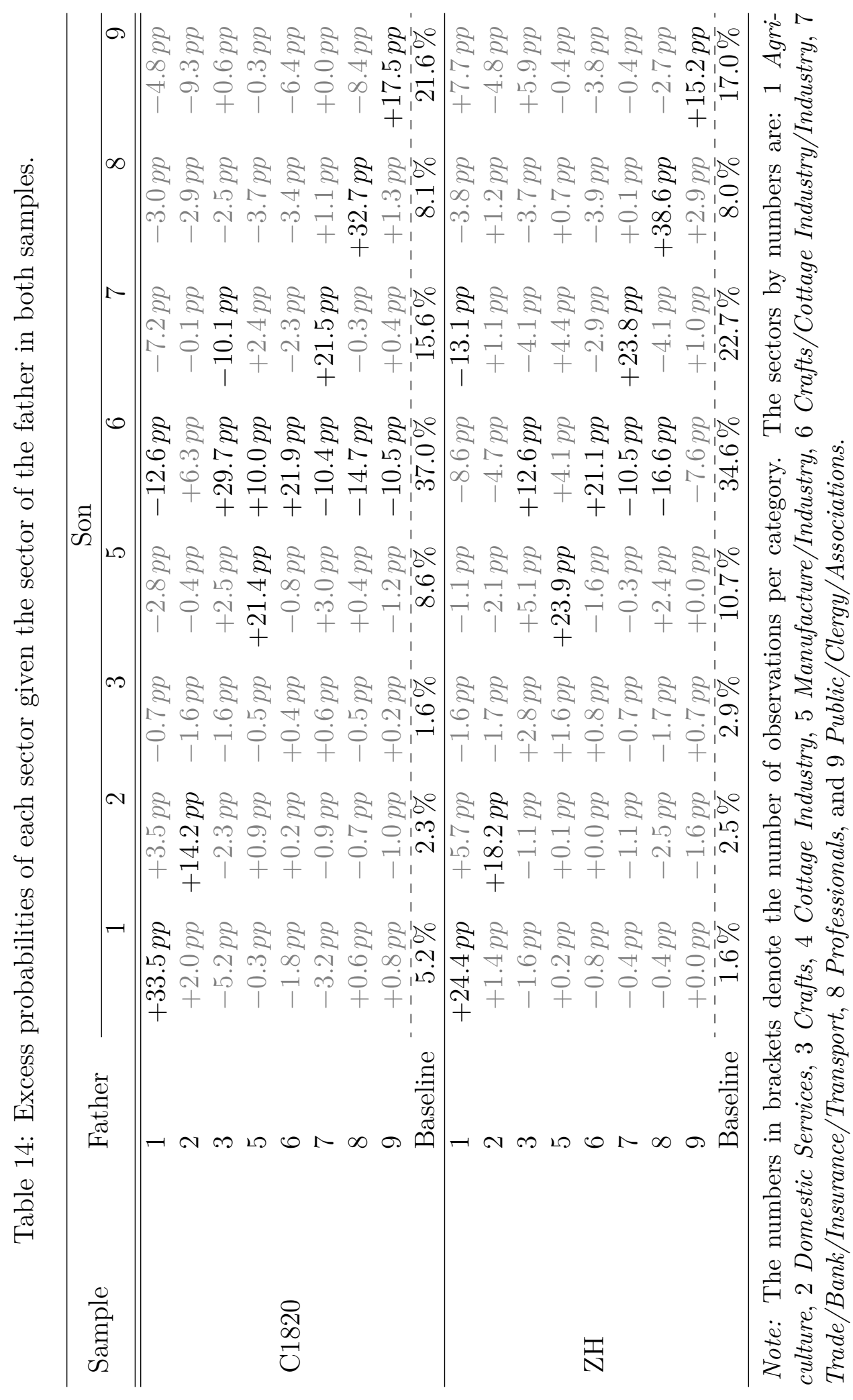

